\title{
Time-of-flight secondary ion mass spectrometry imaging in cultural heritage: A focus on old paintings
}

\author{
Caroline Bouvier, ${ }^{1}$ Sebastiaan Van Nuffel, ${ }^{2}$ Philippe Walter, ${ }^{1}$ Alain Brunelle ${ }^{1 *}$ \\ ${ }^{1}$ Sorbonne Université, CNRS, Laboratoire d'Archéologie Moléculaire et Structurale, LAMS, \\ 4 place Jussieu, 75005 Paris, France \\ ${ }^{2}$ M4I, Faculty of Science and Engineering, Maastricht University, Universiteitssingel 50, \\ 6229CR Maastricht, The Netherlands \\ * Corresponding author: A. Brunelle, E-Mail: Alain.Brunelle@cnrs.fr
}

\begin{abstract}
Time-of-Flight Secondary Ion Mass Spectrometry (TOF-SIMS) imaging is a surface analysis technique that identifies and spatially resolves the chemical composition of a sample with a lateral resolution of less than $1 \mu \mathrm{m}$. Depth analyses can also be performed over thicknesses of several microns. In the case of a painting cross-section for example, TOF-SIMS can identify the organic composition, by detecting molecular ions and fragments of binders, as well as the mineral composition of most of the pigments. Importantly, the technique is almost not destructive and is therefore increasingly used in cultural heritage research such as the analysis of painting samples, especially old paintings. In this review, state-of-the-art of TOFSIMS analysis methods will be described with a particular focus on tuning the instruments for the analysis of painting cross-sections, and with several examples from the literature showing the added value of this technique when studying cultural heritage samples.
\end{abstract}

Keywords: TOF-SIMS imaging; pigments; organic matters (oils and proteins); cultural heritage 


\section{Introduction}

Certain objects and know-how have cultural significance in our societies, that is, they are inherited from a common past and are meant to be preserved and passed down from generation to generation. These can be works of art such as frescoes, paintings or jewelry, but also statues, ruins, and everyday objects such as pottery, tools, remedies, and cosmetics. All of which are a testimony to the skills and technical knowledge of the past societies. The expertise and actions of, for example, curators and restorers play an important role in this generational transmission of cultural heritage. Given the variety of questions that can arise regarding objects made of different structures and materials, combining several disciplines appears to be a beneficial approach. A better understanding of the history of material productions from the past can also be done by relying on the physics and chemistry of their constituent materials. Although microscopic information was in the past inaccessible, the craftsmanship knowledge has taken into account the link between specific processing of materials and the aspect and properties of the crafted objects. Today the possibility to analyze with precision their composition provides insight into the object as it was designed. In the case of old paintings, the chemical identification of organic and inorganic pigments, as well as that of the binders that contain them, provides valuable information about the painter's technique, the nature and origin of the ingredients and their aging, or even their state of degradation. This information can then be combined with the knowledge and expertise of restorers and curators.

A painting is made by successively applying layers of various mixtures of pigments in one or more binders, such as oil, egg, or animal glues. These layers are a few microns to a few hundred microns thick. Particles of colored materials dispersed in this way in more or less transparent matrices will create environments in which the light will be diffused, reflected or absorbed in multiple ways. The superposition of these media - or layers - will then play a role in the optical effects giving the final rendering desired by the artist. The connection between painting work and these optical phenomena was part of the knowledge of painters, therefore the composition of the layers can provide information about the way of working and the intentions of the artist, especially when the appearance or the color of the paint is now changed with the effect of time. Being able to access the internal structure of these layers, each separately, brings an invaluable perspective within the object as it was designed and executed.

Time-of-Flight Secondary Ion Mass Spectrometry (TOF-SIMS) imaging is a surface and volume analysis technique that locates and identifies the chemical composition of a sample at the surface and over a thickness of several microns. It gives access to the organic compounds, by the detection of molecular ions and fragments, and to the mineral composition, and is almost not destructive. It is therefore a method that is increasingly used for the analysis of painting samples, especially old paintings.

Figure 1 shows a schematic of the layers commonly distinguished in old paintings, especially in oils. This is not a unified or exhaustive description of the structure of the paintings, but rather a common scheme and terminology we can refer to in our discussion of the analysis of painting cross-sections. 
The preparation of the support, which can be made of canvas, wood panel, or even slate, is an important part of the work. In the case of canvas, the porosity between the fibers is reduced by the application of a glue with sometimes earth or calcium sulfate or carbonate (sizing) added. Next, a preparation layer is applied to the entire surface to ensure an adherent, luminous and homogeneous support. This coating, also called ground or gesso, is composed of a binder and a white calcium-based material (plaster, gypsum, anhydrite or chalk) making the whole layer opaque. The binder is made of glue or oil, for a lean or fatty preparation, respectively. The lean formula, being more absorbent than oil, may have a beneficial influence on the preservation of the oil layers applied on top, provided that it is not too thick. ${ }^{1}$ A preparatory drawing can be traced on top of this preparation with carbon black, or an iron gall ink used for example by Giovanni Bellini. ${ }^{2}$ A rough drawing can also be made using a weak color mixture, for example a tempera (with water), as well as the imprimatura layers (preparation layers) which can be lightly colored.

Pigments mixed in a binder are then applied in one or more pictorial layers, which are more or less opaque. The desired color and optical effect are generated by the incident light path in these scattering media. ${ }^{3}$ Hue and shine can then be modified by glazes, which are thin transparent layers colored with a small amount of pigment dispersed in a large amount of binder. Finally, a varnish applied to the surface of these successive layers will serve to protect the painting. The transparent varnish will also modify the depth of the image, like a glaze, because the light will travel longer or undergo multiple diffusions.

The pigments are natural minerals or synthetic powders. Some were very rare at the time and highly prized for their quality. Their use and production are linked with the evolution of societies over the centuries. The history of pigments is therefore well documented and studied, whether through the history of art or the history of materials and of trade. ${ }^{4-9}$

Paint binders hold pigments and additives together as the paint film dries. These are organic materials such as drying oils, egg, waxes, resins or collagen-based animal glues. Their composition can vary greatly depending on the recipe used by the painter. Knowing and understanding these recipes, according to the period and place of origin of the painting, is essential in the interpretation of chemical information. For this it is particularly important to rely on historical texts detailing the techniques and old recipes. ${ }^{10}$ In addition, the interpretation of the presence of an ingredient in a layer of the stratigraphy must be based on techniques known and / or appropriate at the time of the painter, as well as on the history of the painting, especially for surface layers, which are more likely to be subject to subsequent changes over the centuries.

\section{Some specificities of cultural heritage samples}

An old painting is a unique object with immaterial value. Analytical procedures must be designed in such a way as to minimize the impact on the object. Preferably, non-invasive techniques are to be used. When analysis techniques require a sample, a compromise is to excise a cross-section of a few hundred micrometer with a scalpel from regions generally already altered, like cracks or holes, or at the edge of the painting. A cross-section has the advantage of simultaneously exposing all the layers of the paint, from the deepest to the varnish, each being 
accessible at the surface of the sample, with the micrometric particles of pigments still lying in the dried binders. Such a cross-section is unique, like the painting from which it has been taken, and should be kept intact as much and as long as possible.

\section{Preparation and handling cross-sections}

Cross-sections (Figure 2) are fragile and generally smaller than a millimeter in size. They are usually embedded in a polymer resin, to ease their handling and avoid causing damage. The resin block is polished until the sample is exposed at the surface.

An advantage of this type of sample is the possibility of analyzing the same surface with several analysis techniques, in order to extract the maximum amount of complementary information. Knowing the history of the sample handling and former preparation procedures is of importance in the effort to remove any surface contamination. An example is shown in Figure 2 , where the sample in question was analyzed by scanning electron microscopy to image and identify the pigments before carrying out the TOF-SIMS analyses. As a result, the sample was delivered with its surface covered with a thin layer of metal to make it conductive for the SEM analysis, which needed to be removed for the surface analysis using TOF-SIMS. Indeed, for some techniques like reflected light microscopy, an immersion oil can be used to improve the image quality. ${ }^{11}$ Silicon-rich contaminants, to which TOF-SIMS is very sensitive, can arise from several sources, such as oil from vacuum pumps or the polymer paste used to attach the resin blocks on instrument holders or inside boxes.

To ensure the surface of the cross-section is flat and clean, the use of a microtome or ultramicrotome has been shown to be particularly effective. ${ }^{12}$ Sections can be made with a thickness of a few microns up to 10-20 $\mu \mathrm{m}$ using a microtome or about $100 \mathrm{~nm}$ using an ultramicrotome. Although it is usually easier to perform the analysis directly on the surface of the remaining block, because the sections are very fragile. Analytical interferences related to the presence of the embedding resin, in particular infiltration into porous areas of the sample, have led to innovations in the embedding procedure in recent years, like the use of a silver chloride salt barrier. ${ }^{13}$

\section{Old painting samples}

As already explained above, a painting is a multilayer mixture of organic and inorganic materials. In the following we focus on paintings made between the 15th and 17th centuries. One of the challenges when studying such objects is the fact that the materials in the paintings likely interacted with each other and with the environments in which they were evolving and kept for several hundred years. The detailed history of the painting is sometimes difficult to piece together, in particular considering possible alterations, modifications or restorations made after the painter's work.

Pigment particles can induce chemical reactions in the surrounding binder. ${ }^{14-16}$ They can often be identified by optical microscopy in polarized light ${ }^{8}$ or by elemental analyses.

The identification of binders after drying, aging and potential interactions is one of the main issues in the analysis of old paintings. Binders can be roughly classified according to their 
composition: those containing proteins and those containing lipids (Figure 3). Oils can be distinguished from glues with chemical analysis techniques able to detect both proteins and fatty acids, but egg yolk, one of the common painting binders in art history, contains both proteins and fatty acids. One must also consider the cases where several binders are mixed. Before the second half of the 20th century, the predominant idea was that in Italian painting, the use of egg was replaced during the 15th century by drying oil, in part by the influence of Antonello of Messina (1430 - 1479). He would have brought with him the secrets of the Flemish technique allowing for remarkable transparency effects. This idea is largely based on literature from the $16^{\text {th }}$ century, such as Lives of the best painters, sculptors and architects by Giorgio Vasari (1550). Recent chemical studies indicate that the transition between the use of the egg and that of the oil is more gradual than initially assumed, with the combined use of egg being still persistent from the 15th onward. Egg and oil were used separately in stacked layers, or mixed with oil in the same, in particular in emulsion in the hypothesis of a technique referred to as "tempera grassa". ${ }^{17-19}$

Regarding the link between the organic matter which can actually be detected and that which had been prepared by the painter, analytical techniques cope with many unknowns. Indeed, there are the variability of recipes throughout the art history and according to the geographical location, the possibility of mixtures, the drying processes, as well as the different interactions between the pigments and the external environment. Many attempts to clarify this have led to methodological developments over the past decades, such as staining or chemical tests to identify the origin of proteins, ${ }^{19-27}$ and numerous studies on drying painting films and on relevant chemical markers from organic matter likely to be found in old paintings. ${ }^{28-32}$

\section{Examples of interactions between pigments, binders, and surrounding}

A wide variety of binders and pigments have been used throughout history, and a multitude of binder / pigment combinations can be encountered. Lead white which is one of the most commonly used pigments in the history of art, and lead oxide (litharge) is added to oils to speed up drying or improve dry film properties. ${ }^{8,33}$ Among the reactions that can occur between the binder and a pigment, the saponification of triglycerides by lead is therefore particularly studied, because it is linked both to the initial preparation of the oil and to a degradation phenomenon frequently observed in old paintings. ${ }^{14,34-37}$ Recent studies seek to establish the link between the formation of soaps involving several elements present in pigments, such as lead, copper and tin. ${ }^{38}$

The interaction of copper-based pigments, and in particular verdigris (copper acetate), with fatty or protein binders has also been the subject of much research, as this can lead to changes in the color of the glaze on the surface, completely changing the look of the work concerned. ${ }^{2,8}$

The blackening of vermilion, which is a red mercury sulfide, and the discoloration of red lacquers imply radical modifications in the shadows of red clothes in particular, as observed in painting by Giovanni Bellini for example..$^{2,11}$ 


\section{Analytical techniques applied to old paintings}

Because old paintings are heterogeneous and hybrid organic-inorganic materials, suitable analytical techniques are those that can provide information about the organic and / or inorganic composition while tackling a difficult accessibility and singularity of the sample. The literature shows that over the past few decades, more and more techniques are being used for the analysis of old painting samples. In the following paragraph some of the most frequently used techniques are briefly described along with their main characteristics and a selection of references from the literature (see Table 1).

Infrared (FTIR) and Raman spectroscopies provide structural information on molecules and minerals. Short-Wave Infrared (SWIR) hyperspectral imaging enables one to scan the surface of a painting with spectral information for each pixel. Scanning electron microscopy (SEM) can be used with secondary electron imaging, with backscattered electrons, or can offer a chemical analysis by X-ray spectrometry (Energy-Dispersive X-ray Spectroscopy, EDS). This is well suited for the study of pigments and nanometer spatial resolutions can be reached. MicroX-ray diffraction $(\mu$-XRD) provides structural identification of materials having a spatial structure (crystal or semi-crystal), and X-ray fluorescence is a method with which one can map materials, and then characterize the inorganic composition of the entire surface of a painting. In addition, this method can be portable with small size devices.

Mass spectrometry is one of the most suited techniques for the analysis of organic binders, with many methods providing a molecular analysis, and in some cases a structural analysis. In this field, gas chromatography coupled with mass spectrometry (GC-MS) stands out. However, it does not allow imaging and does not provide access to the analysis of pigments, in addition to being micro-destructive and requiring a laborious sampling protocol. A comparison of the different mass spectrometry imaging methods can be found in Table 2 .

\section{TOF-SIMS mass spectrometry imaging}

Time-of-flight secondary ion mass spectrometry imaging analysis is a surface analysis method which aims at detecting and identifying, while retaining lateral information, simultaneously both molecular and inorganic compounds (along with any element) on the surface of a sample. The surface thickness examined is of the order of ten nanometers or less. The material is sputtered and ionized, and the generated ions are analyzed according to their mass to charge ratio $(\mathrm{m} / \mathrm{z})$. The combination of chemical and spatial information makes mass spectrometry applicable to various kinds of samples (mineral, organic, biological), without any knowledge of the sample being necessary a priori. While SIMS was first developed towards surface imaging in the sixties, ${ }^{39}$ TOF-SIMS now achieves a lateral resolution of less than one micrometer and stands out for the simplicity of sample preparation. The most important limitation is the need for a clean and flat surface, and a sample whose dimensions are adapted for a vacuum analysis chamber. This is particularly the case for complex, heterogeneous, small, hard or valuable samples, but resin embedding followed by ultra-microtomy cutting has been developed for this purpose. ${ }^{12}$ 
The early SIMS studies were limited to small fragments of molecules or inorganic compounds because of the damage induced by the impact of the primary ions. The damage to the surface can be defined by the disappearance cross section $\sigma$ which represents the individual area damaged by a single primary ion. The detection of (quasi-) molecular ions by Benninghoven in 1973 at a low dose of primary ions $\left(<10^{13}\right.$ ions $\left./ \mathrm{cm}^{2}\right)$ encouraged the analysis of organic compounds and the development of TOF-SIMS instruments. ${ }^{40,41}$ Since then, many developments have made TOF-SIMS imaging a technique applied to various fields, including the analysis of heritage objects.

SIMS relies on the emission of charged species, called "secondary ions", from the surface of the sample bombarded by a beam of high-energy particles capable of breaking any chemical bond. This beam is made of pulses of "primary ions", having a kinetic energy of a few tens of kiloelectronvolts, and focused on the surface, with a diameter varying from 0.4 to $2 \mu \mathrm{m}$. By mass separation and detection of secondary ions, TOF-SIMS imaging can record the chemical composition of a surface, by recording ion density maps which are called ion images.

The impact of the primary ions induces collision cascades as energy is transferred to the atoms in the sample. These collisions fragment matter, and elements or fragments of molecules are emitted from the outermost layers when the kinetic energy exceeds the energy of the surface bond. This desorption-ionization phenomenon is the emission of secondary ions, which are characteristic of the surface. Molecular ions, however, can be emitted only at a certain distance from the point of impact, where the energy received is lower. Since the formed species are extracted to the mass analyzer by the application of an electrical voltage, only ions can be analyzed and detected. Yet, the large majority of the particles or fragments emitted are neutral and about $0.01 \%$ only of the sputtered material is ionized. Despite many applications, the ionization-desorption process remains poorly understood. More details can be found in the books edited by Vickerman \& Briggs and by van der Heide. ${ }^{42,43}$

The early primary ion sources were emitting beams of inert gases $\left(\mathrm{He}^{+}, \mathrm{Ar}^{+}, \mathrm{Xe}^{+}\right)$. These ions are relatively easy to produce but not to focus on a small area while still maintaining sufficient current. The development of liquid metal ion guns ( $\mathrm{LMIG}, \mathrm{Ga}^{+}$) in the 70 s made possible to overcome this difficulty, ${ }^{44}$ since the diameter of the beam can be less than $100 \mathrm{~nm}$. High resolutions for imaging have been achieved thanks to this. Until the end of the nineties, the poor yield of secondary ions with atomic ion impacts limited molecular information under static conditions. To improve this efficiency, the first studies using polyatomic ion beams discovered a nonlinear enhancement of the secondary emissions of ions and neutrals. This was first observed by Rol et al. in 1960 and Andersen \& Bay in 1974. ${ }^{45,46}$ The secondary ion yield induced by a cluster of $n$ atoms is greater than that obtained after $n$ impacts of individual atoms at equal speed. Secondary ion emission and sputtering (emission of neutrals) were extensively studied by Le Beyec and co-workers, with impact energies ranging from a few $\mathrm{keV}$ to a several tens of $\mathrm{MeV}$, and with gold and carbon clusters (including $\mathrm{C}_{60}{ }^{+}$) having different number of constituents. ${ }^{47-51}$. The number of atoms in the projectile appeared to be a key parameter. ${ }^{52}$ The implementation of polyatomic ion sources led to the rise of molecular imaging in TOF-SIMS 
since the 2000s, first with LMIG emitting gold clusters, ${ }^{53-55}$ and soon after with LMIG emitting bismuth clusters, ${ }^{56,57}$ which is now the most widely used ion source for molecular imaging. The performance of bismuth clusters against gold cluster is similar regarding the secondary ion emission, but the beam current achieved with the bismuth LMIG is higher, and a smaller beam diameter can be reached. $\mathrm{Bi}_{5}{ }^{2+}$ gives very good sensitivity for imaging (useful lateral resolution $<1 \mu \mathrm{m}$ ), for example in molecular mapping in tissues, but the low beam current requires long acquisitions. Currently, $\mathrm{Bi}_{3}{ }^{+}$ions are the most widely used in high resolution imaging of organic and biological samples. This is explained by their high sensitivity due to the good yield of secondary ions coupled with a spatial resolution of the order of $400 \mathrm{~nm}-2 \mu \mathrm{m}$ thanks to a narrow focusing of the beam, as well as higher contrasts in imaging. The in-depth damage induced by the impact of $\mathrm{Bi}_{3}{ }^{+}$ions is noticeable but does not exceed $10 \mathrm{~nm}$ under static conditions. However, because of the damage, obtaining molecular ions above 1,000 Da remains challenging, which in particular prevents the analysis of whole proteins. Large polyatomic cluster ion sources such as fullerene ions $\mathrm{C}_{60}{ }^{+}$, or massive argon cluster ions $\operatorname{Ar}_{n}{ }^{+}(\mathrm{n}=100$ $10,000)$ are interesting for biological imaging, because they generate a soft ionization, that is to say with a low amount of energy transferred by primary ions. ${ }^{58,59}$ They allow an improvement in the sputtering and emission yields of intact secondary ions (molecular, even for peptides or small proteins). However, compared to liquid metal ion sources, it is more difficult to focus them at the proper level for high resolution imaging while maintaining a reasonable ion current. They are thus more intended to sputter the very first layers of the surface with a very limited damage to the underlying material (penetration of only a few Ångströms). This makes them attractive for the gentle sputtering of organic matter, especially massive argon clusters which therefore allow the best depth resolution. The use of such sources in TOF-SIMS applies in particular to in-depth analysis and 3-D imaging by dual beam depth profiling in pure organic materials. ${ }^{60,61}$ Using ions from benzylpyridinium salts, which are known as "chemical thermometers", ${ }^{62} \mathrm{Fu}$ et al. have studied the internal energy distribution of secondary ions when emitted after the impact of bismuth and argon clusters. ${ }^{63}$ They have found that large argon clusters, of which each constituent atom bears a low amount a kinetic energy, transfer less internal energy to the secondary ions than bismuth clusters like $\mathrm{Bi}_{3}{ }^{+}$.

\section{Focusing modes of the primary ion beams}

The most frequently used focusing mode is called High Current Bunched (HCBU). It allows a mass resolution of several thousand $(\mathrm{M} / \Delta \mathrm{M}$ up to 8,000 , FWHM, on a flat surface) thanks to the bunching of the primary ions in very short pulses $(<1 \mathrm{~ns})$ on the sample surface plane. It also provides a high primary current, and then a relatively short analysis time. However, with this mode the primary ion beam diameter is about $3 \mu \mathrm{m}$, thus limiting the lateral resolution to this value in imaging. With the so-called Burst Alignment (BA) mode, a high spatial resolution can be reached with a beam diameter of about $400 \mathrm{~nm}$.

Here it is necessary to specify that if the pixel size is never less than the primary ion beam diameter, then the spatial resolution, also sometimes called lateral resolution, is defined by this pixel size. It is admitted to set a pixel size equal to the diameter of the primary ion beam and to say indifferently that this corresponds to the spatial resolution. This will always be the case 
thereafter. If the pixel size is smaller than the primary ion beam diameter, then there is oversampling, and the spatial resolution remains limited by the latter.

However, the primary ion pulses cannot be bunched and the pulse duration is $\sim 100 \mathrm{~ns}$. The analysis time is longer because the primary ion current is $\sim 5$ times smaller than in the HCBU mode (as an example, $0.08 \mathrm{pA}$ in BA mode, and $0.40 \mathrm{pA}$ in $\mathrm{HCBU}$ mode for $\mathrm{Bi}_{3}{ }^{+}$ions being pulsed at a frequency of $10 \mathrm{kHz}$ ). To have both good mass and spatial resolutions, which is essential to minimize the ambiguity on the secondary ion peak assignments in the mass spectrum, the BA mode is coupled with a delayed extraction (DE) of the secondary ions. The mass resolution of the $\mathrm{BA}+\mathrm{DE}$ mode reaches several thousand and the spatial resolution can go down to $400 \mathrm{~nm}$. This mode is particularly interesting when analyzing very small and valuable samples. Details on these different modes can be found in specific publications. ${ }^{56,64,65}$

\section{Time-of-flight mass analyzer in a TOF-SIMS instrument}

The secondary ions are extracted and accelerated by a uniform electrostatic field created by a voltage applied between the surface of the sample (at ground) and the extractor (at potential). In that case the time of flight of the secondary ions is a linear function of the square root of the mass-to-charge ratio $\mathrm{m} / \mathrm{z}$. The mass resolution $\mathrm{R}=\mathrm{m} / \Delta \mathrm{m}$, which is also equal to half of time resolution $t / \Delta t$, is very sensitive to phenomena causing ions of the same mass to arrive at the detector at slightly different times, such as the duration of the pulses of the primary ion beam, the emission process which forges the initial kinetic energy distribution in the emitted ions, the surface topography, or the inhomogeneity of the surface potential. An electrostatic reflector, compensates for the consequent time distribution, thus improving $\mathrm{R} .{ }^{66}$ More details about reflectrons can be found in a book written by Cotter. ${ }^{67}$ The delayed extraction method after using the BA mode has been characterized in detail by Vanbellingen ${ }^{65}$ and has now become a routine method in TOF-SIMS. Ions of the same $m / z$ but being produced at different times, in particular because of the long duration of the primary ion pulse, are grouped together in time at the detector. The extraction voltage of the secondary ions is applied after a delay, equal to the duration of the primary ion pulse, so that the emitted ions are not subjected to any electric field just after their emission. They fly first with only their initial kinetic energy (a few eV), then, when the high voltage extraction is applied, the first emitted ions have travelled a certain path so that they will be less accelerated than the last ions emitted. The result will be a time focusing of all secondary ions of the same $\mathrm{m} / \mathrm{z}$ at the detector. A drawback of this method is the loss of sensitivity by a factor of $\sim 2$, and a loss of the low mass secondary ions (below $\sim m / z 20$ ), but this method also induces an attenuation of topographic effects, so that ultimately the mass resolution is sometimes even better than in $\mathrm{HCBU}$ mode, reaching $\mathrm{M} / \Delta \mathrm{M}=8,000$, depending on the instrument. Calculations and experience show that the value of this extraction delay must be equal to the duration of the primary ion pulse to have the best mass resolution. ${ }^{65}$

With insulating samples, the potential at its surface is different than that of the holder. It was observed by Van Ham et al. that uncorrected surface potential would prevent proper detection in embedded samples from cultural objects, ${ }^{68}$ who stressed the need for preparation procedure further adapted to the increasing sensitivity of the techniques. To ensure the best extraction, transmission, and resolution for the secondary ions, it is therefore necessary to tune 
the analyzer to the real kinetic energy that these secondary ions hold. This can be done by measuring it, taking advantage of reflectron. As an example, the potential at the surface of a painting sample embedded in a several mm thick resin block can differ by several hundred volts, while the applied extraction voltage is $2 \mathrm{kV}$. This fine tuning of the mass analyzer was studied by Seyer et al. with plant tissues, ${ }^{69}$ and a detailed study of the implications of this phenomenon on painting cross-sections was recently published by Bouvier et al. ${ }^{70} \mathrm{~A}$ former possible method to avoid variations in the extraction field was to place a slotted stainless steel plate on the analyzed surface of cross section, which has the benefit to keep a part of the surface conductive. ${ }^{71}$ Coating the surface of a cross-section with a nanometric gold layer also reduces the charge on the surface, while improving the yield of fatty acids secondary ions. ${ }^{72}$

\section{Mass spectrum calibration}

Since the initial kinetic energy distribution of the secondary ions is narrow, the relationship between the time-of-flight and the square root of $\mathrm{m} / \mathrm{z}$ is always linear over the entire mass range. This is the case for the HCBU mode with a continuous extraction. In this case the mass calibration can simply be achieved with "internal" ions, such as $\mathrm{H}_{2}{ }^{+}, \mathrm{H}_{3}{ }^{+}, \mathrm{C}^{+}, \mathrm{CH}^{+}, \mathrm{CH}_{2}{ }^{+}, \mathrm{CH}_{3}{ }^{+}$, $\mathrm{C}_{3} \mathrm{H}_{2}{ }^{+}$and $\mathrm{C}_{2} \mathrm{H}_{5}{ }^{+}$in positive ion mode and $\mathrm{CH}^{-}, \mathrm{CH}_{2}{ }^{-}, \mathrm{C}_{2}^{-}, \mathrm{C}_{3}^{-}, \mathrm{C}_{4}^{-}, \mathrm{C}_{2} \mathrm{H}^{-}$and $\mathrm{C}_{4} \mathrm{H}^{-}$in negative ion mode. This calibration can then be refined by adding greater mass ions. In the case of the $\mathrm{BA}+\mathrm{DE}$ mode, the linear relationship is lost because the energy deficit of the secondary ions emitted depends on their $\mathrm{m} / \mathrm{z}$ ratio. It is therefore necessary to calibrate first as above for the mass range below $m / z 100$ because the deviation is small. For heavier mass ions, the deviation is notable (of the order of $0.1 \mathrm{Da}$ ) and heavy ions must be used, for example ions from lead or calcium oxides, which are frequently present in paint cross-sections. If spectra are compared between different samples, it is necessary to calibrate all the spectra with the same ions detected in all samples.

\section{TOF-SIMS imaging}

The microprobe mode imaging involves focusing the ion beam to scan an area which is divided by a number of pixels. The mass spectrum in each pixel is correlated with the position of that pixel, allowing spatial information to be reconstructed from the total mass spectra after acquisition. In this way, ion density maps are formed, called ion images.

In the case of complex samples, imaging can help decipher mass spectra using the colocations of fragments, as this usually implies that they come from the same molecule.

The TOF-SIMS technique in its current configuration is well suited to the surface analysis of biological samples, and this is the mass spectrometry imaging method that offers one of the best spatial resolutions. The mapping of small biological molecules on the surface of wood or animal tissues (lipids, biological markers) or proteins forms a comprehensive literature. For example, the imaging of plants and microorganisms allows precise access (spatial resolution of around $400 \mathrm{~nm}$ in some cases) to the spatial distribution of metabolites, minerals and lipid species in durable wood such as larch or Dicorynia guianensis. ${ }^{73,74}$ In the latter case, the particular location of the compounds helps to understand the durability of these woods. It is 
also possible to study pathologies using the spatial distribution of markers, or the absorption of drugs by an organ or in single cells. ${ }^{75-77}$

3D-imaging can be achieved with TOF-SIMS by introducing the entire sample in the instrument. Instead of performing successive sections and analyzing each of these sections in 2D, a first cluster ion source sputters away layer by layer the material, and a second source (or the same in some instrument configurations) performs the analysis of the newly exposed intact surface between each sputtering step. Usually, TOF-SIMS 3D-imaging is achieved in organic samples with a $\mathrm{Bi}_{3}{ }^{+}$ion beam for analysis and $\mathrm{Ar}_{\mathrm{n}}{ }^{+}(\mathrm{n} \sim 2,000)$ ion beam for sputtering, in a socalled dual beam depth profiling. This makes possible to couple the advantages of both sources, the LMIG delivering a beam focused down to a few hundred nanometers, and being very efficient for surface analysis of organic ion species, and the massive argon cluster ion source being efficient for a gentle layer by layer sputtering. By reconstruction of the data (stacking of the different ion images and realignment) one can form 3D images. Dual Beam TOF-SIMS imaging has been evaluated for lipids on rat brain sections, to increase sensitivity by accessing underlying intact material and then summing the intensities. On a $10 \mu \mathrm{m}$ thick tissue sample, the sensitivity can be increased by more than 300 for an analyte. ${ }^{60}$ A limitation of this technique is the unexpected evolution of the composition depending on the depth, especially with some lipid species like cholesterol which migrates and concentrates close to the surface under vacuum if the sample is not kept frozen during the analysis. ${ }^{78}$ The detection and localization of a metabolite of pharmaceutical interest inside a plant vesicle (Macaranga vedeliana) confirms the ability of TOF-SIMS 3D-imaging for the precise spatial localization of molecules in complex samples, as well as its flexibility regarding different sample preparations (freezing). ${ }^{61}$ This method is therefore a very interesting alternative to localization methods based on the detection of chemical markers.

\section{Matrix effects}

Secondary ion emissions are very dependent on the compounds surrounding the desorbed species. This environment can amplify or inhibit the ion emission, which biases any attempt of quantitative measurement. This phenomenon is very difficult to predict and requires working only in relative quantification. Cholesterol, for example, seems to induce such an effect on many other lipid ion species. ${ }^{79,80}$ Although the analysis of lipids by TOF-SIMS is therefore subject to the matrix effect, in the case of lipids of interest for heritage samples, this does not necessarily preclude comparing relative quantifications. One of the indicators used to identify binders containing fatty acids is indeed the ratio of palmitate $\left(m / z 255.2, \mathrm{C}_{16} \mathrm{H}_{31} \mathrm{O}_{2}{ }^{-}\right)$over stearate $\left(\mathrm{m} / \mathrm{z}, 283.2, \mathrm{C}_{18} \mathrm{H}_{35} \mathrm{O}_{2}{ }^{-}\right)$ions. These ions have very similar molecular structure and mass, so their secondary ion emission efficiency can be assumed to be similar, allowing comparison of the relative intensities of their peaks. ${ }^{37}$ However, it has been shown in GC-MS that, in the case of mixtures of binders, or in the presence of particular pigments, and because of the aging of the paint films, the value of the ratio can be modified. ${ }^{17,81}$ By extension this can also occur in TOF-SIMS if one consider possible local matrix effects, and one has therefore to remain cautious when considering these ratios. 


\section{Reliability of TOF-SIMS imaging}

TOF-SIMS is established as reproducible in terms of peak intensity and spectrum. TOFSIMS imaging also has good repeatability for various kind of samples, and especially biological samples. The quality of the ion images is repeatable, in other words the difference is not significant between the images recorded successively on adjacent sections, or on different areas of the same section being histologically comparable. This has been demonstrated on rat brain sections ( $p$-value of the t-test $<0.05$ ), and sample preparation issues emerged as being the limiting parameter. ${ }^{82}$

\section{Ion images and region of interest (ROI)}

In mass spectrometry imaging an ion image can be drawn from each ion peak, thus providing precise localization of the various species which are detected at the sample surface. The colocalization of different ions can also help in the identification of the species in the absence of a structural analysis by the lack of a tandem mass analyzer. The inverse operation is also very helpful. It consists in drawing regions of interest, on the basis of a histological area, or in painting samples on the basis of the localization of a few ions which, for example, determine the limits of pictorial layers. Localized mass spectra can then be extracted from these ROIs. This is a very important tool which can in some cases give rise to ion peaks which would otherwise be buried in the total ion spectrum. In addition, provided the different ROIs are normalized over their individual surfaces, the intensities of ion peaks can be precisely compared between, thus providing an internal relative quantification.

\section{New developments}

To address the need for unambiguous molecular identification in TOF-SIMS, new instruments have been developed with a tandem mass spectrometry capability. One instrument, developed by Physical Electronics, is able to analyze by MS/MS a secondary ion selected in the mass spectrum, while all the other ions are analyzed and imaged by simple MS. ${ }^{83}$ This coupling of tandem mass spectrometry to imaging has been applied to obtain images of metabolites in tropical wood samples, and to precisely identify these compounds by MS/MS, thus providing new information of their biosynthesis pathway. ${ }^{84,85}$ However the first TOFSIMS instrument to demonstrate MS/MS capabilities has been the J105 developed by IONOPTIKA. In this instrument collisions were achieved between the secondary ions and argon gas in a field free region before the reflectron and after the exit of the buncher that samples the secondary ion stream. ${ }^{86}$ The $\mathrm{J} 105$ can now be fitted with a water cluster primary ion source, which might be useful for painting analysis, ${ }^{87}$ although not tested with such samples, as far as we know. IONTOF has recently developed a new generation of instrument, with an analyzer reaching a mass resolution of $\mathrm{M} / \Delta \mathrm{M}=30,000$, and $\mathrm{MS} / \mathrm{MS}$ capability with a resolution of 3,500 on the selection of the precursor ion. As an option of this instrument an Orbitrap analyzer can be added, replacing the above tandem TOF by reaching a mass resolution of 280,000 with a mass measurement accuracy of $\sim 1 \mathrm{ppm}$ only. ${ }^{76,88}$ With this instrument, the bismuth cluster ion source delivers a beam which can be focused down to $50 \mathrm{~nm}$, even with clusters and not only with atomic projectiles. Combined with the delayed extraction and the 
MS/MS capabilities, this can in the near future pave the way for new analytical strategies for cultural heritage samples.

\section{Other applications}

Since TOF-SIMS imaging is well suited for the analysis of complex organic and/or inorganic samples, its applications extend far beyond the analysis of heritage objects. It is a method of choice for the study of biological samples of diseased organs, ${ }^{76,89-91}$, insects, ${ }^{92}$ plants, ${ }^{69,93}$ in particular the study of metabolites present in wood. ${ }^{73,74,84}$ The possibility of detecting inorganic and organic ions in parallel makes this technique suitable for the analysis of biominerals, bones, fossils, rocks, ${ }^{94-97}$ illicit traces in fingerprints, ${ }^{98}$ or even banknotes ${ }^{99}$

\section{TOF-SIMS imaging for the analysis of cultural heritage}

\section{samples}

As seen before, Cultural Heritage samples are complex and heterogeneous systems, which can have been modified by their environment or by human operations, sometimes over the course of centuries. The current performance of TOF-SIMS can combine high mass resolution with high spatial resolution with delayed extraction, directly on the surface of interest. Its application to this type of samples is then particularly suitable, in particular with cross-sections. Indeed, this chemical imaging technique combines imaging at a microscopic scale with mass spectrometry, which allows to study localization and composition in complex heterogeneous organic and mineral mixtures. It is therefore expected to become a method of choice for simultaneously mapping the binders and pigments in old paintings, as well as their possible interaction or degradation products. Another advantage is the ability to directly analyze the insulating surfaces, and to map molecular ions on very small samples with a spatial resolution of less than $1 \mu \mathrm{m}$. This matches the scale of the internal structures of the paint layers, because the thinnest layers are only a few microns thick, and the size of the pigment particles can vary from a few hundred nanometers to several tens of microns. Finally, static TOF-SIMS is not particularly destructive - it just explores the first layers - and then allows additional analyses to be carried out on the same surface, or at least on the same sample. Care must be taken not to apply too high a dose of primary ions to the surface, to ensure that the material being analyzed remains intact (working below the so-called static SIMS limit). A wave of proof of concept applications of secondary ion mass spectrometry on several types of heritage objects occurred in the early 2000s, as reviewed by Adriaens et al. in 2006. ${ }^{100}$ It shed light on the input of the technique into the issues associated with heritage samples.

\section{Archaeological artefacts}

The use of uric acid from snake urine as a white pigment has been established in Dogon ritual art sites in Mali. ${ }^{101}$ The identification of uric acid rather than urate salts suggested a pigment treatment or an environmental degradation by water (see Figure 4). The analysis of micro-samples from the patina at the surface of ritual statuettes was also made, identifying and localizing minerals, proteins indicating the use of blood, starch and lipids. ${ }^{12,102,103}$ Only amino 
acid fragments are detectable by a typical TOF-SIMS instrument, but if they are colocalized, the presence of protein can be inferred. ${ }^{104}$

\section{Paintings}

The discolored particles of blue smalt pigment in drying oil could be imaged from core to surface, allowing a better understanding of the chemical interactions taking place in a wellknown pigment/binder alteration. ${ }^{105}$ TOF-SIMS imaging has been applied to the characterization of the green pigments used in the Issenheim Altarpiece (1516, Grünewald), establishing the possible presence of atacamite (copper salt), which partially seemed to have changed into copper carboxylates (see Figure 5). ${ }^{106}$ In another study, by accessing the composition within the degraded paint layers of about a few micrometers while retrieving molecular information about the degradation products, a new hypothesis for the degradation mechanism of vermillion was proposed by Keune (see Figure 6). ${ }^{11}$

As shown by the study on Rebecca and Eliezer at the Well, painted around 1664 by Nicolas Poussin (1594-1665), TOF-SIMS imaging on a single sample combined with thorough and meticulous data processing can answer various questions regarding composition, degradation, impurities, dispersion, interactions, drying, origin of ingredients and raw materials, painter's technique, etc. ${ }^{107}$ Ion images of the whole surface, mass spectra extracted from ROIs as well as line profiles through the layers of the cross-section can all provide information about the composition of grains and layers as well as interactions between compounds. The colocalization of lead oxides with fatty acids and particular ions aided the understanding of the formation of lead soaps, which is an important issue in conservation science ${ }^{37}$ and has been observed during the analysis of Portrait of Nicolaes van Bambeeck painted in 1641 by Rembrandt van Rijn (1606/1607-1669), ${ }^{108}$ and The Descent from the Cross painted by Rogier van der Weyden (1399/1400-1464) ${ }^{71}$ In this study of the Portrait of Nicolaes van Bambeeck, it has also been shown that Rembrandt could have used small scraps of dyed fabric as a raw coloring material. ${ }^{108}$. High quality spectral data is needed to identify the different compounds, so the possibility to combine both high mass and lateral resolution thanks to the delayed extraction mode $(B A+D E)$ led to a significant advance. Small grains of two different earth pigments have been differentiated based on their chemical compositions. ${ }^{107}$ However, because the mass resolution obtained with a conventional TOF-SIMS instrument is only several thousands, it is necessary to obtain reference mass spectra of binders and pigments, under identical experimental conditions, to help the ion peak assignments. The choice of the reference materials is very important, in particular regarding the preparation and the ageing of the organic materials, since original materials are scarcely available.

Supplementary analyses with other techniques are needed to confirm and support the TOFSIMS data. Both SEM and optical microscopy are of great help in the understanding of the TOF-SIMS data and particularly to draw the ROI and determine the areas to be profiled. The extraction of the mass spectrum from the ROI associated with a specific layer and its comparison with reference spectra can directly provide the type of binder used for this layer, or an estimate of the origin of the glue, or the type of oil by using peak intensity ratios. ${ }^{70,71,107}$ This 
can replace destructive methods like GC-MS, and these ratios are obtained in a spatially resolved fashion.

\section{Lipids}

The major advantage of TOF-SIMS imaging in the context of the analysis of old paintings is its capability to detect organic molecules at a micrometer scale and simultaneously identify pigments. On the basis of the classification shown in Figure 3, the ability to detect both lipids and amino-acid fragments (proteins) can provide a great deal of information on the binders used in each painting layer.

Lipids are molecules that are easily detected in both negative and positive ion polarities during TOF-SIMS analysis (see Table 3). It is possible to distinguish different fatty acids, triglycerides or di- and monoglycerides. Triglycerides are generally fragmented by the primary ion impact, and detected only through their fragment ions, fatty acids, mono and diglycerides. The negative ion mode shows the total distribution of monocarboxylic acids, originating either from free fatty acids or from fragments of glycerides, and the positive ion mode indicates whether they are free or bound to an ester. Ion peak series with mass intervals of $12 \mathrm{u}(\mathrm{C}), 14 \mathrm{u}$ $\left(\mathrm{CH}_{2}\right), 26 \mathrm{u}\left(\mathrm{C}_{2} \mathrm{H}_{2}\right)$ and $28 \mathrm{u}\left(\mathrm{C}_{2} \mathrm{H}_{4}\right)$ are typically observed for lipids with long aliphatic chains.

In recent years various ToF-SIMS studies on biological samples have identified many lipid species. TOF-SIMS imaging of tissue sections from diseased livers have for example led to a study of the localization differences between different lipids as well as changes in lipid composition, linked to the stage of the steatosis, thanks to peak intensity ratios. ${ }^{89}$ The mass resolution of TOF-SIMS, however, limits the assignment of the ion peaks, especially above several hundreds of mass units.

The literature on the analysis of oil-based paint by TOF-SIMS continued to expand over the last twenty years with recent reviews compiling many referenced ions. ${ }^{109-111}$

Plant oils used in painting are rich in saturated mono-carboxylic fatty acids, in particular palmitic $\left(\mathrm{C}_{16} \mathrm{H}_{32} \mathrm{O}_{2}\right)$ and stearic $\left(\mathrm{C}_{18} \mathrm{H}_{36} \mathrm{O}_{2}\right)$ acid. These two fatty acids are also the only ones which remain detectable after aging of the oil, and their intensity ratio $(\mathrm{P} / \mathrm{S})$ is frequently used as a marker of the nature of the oil in conservation sciences. ${ }^{112,113}$ In addition to the P/S value that correlates with the nature of the binder, the monounsaturated oleic acid $\left(\mathrm{C}_{18} \mathrm{H}_{34} \mathrm{O}_{2}\right)$ is of interest. A low $\mathrm{O} / \mathrm{S}$ ratio combined with the detection of short chain acids indicates that the oleic acid has been oxidized. According to Colombini et al. this $\mathrm{O} / \mathrm{S}$ ratio can be considered an "oxidation index" and most old paints show a ratio of about 0.2 to 0.5 , while it can be as high as 0.7 for egg. ${ }^{114,115}$ The drying mechanism of an oil paint is a polymerization by oxidation of the chains by free radicals which begins on the chains of unsaturated fatty acids. ${ }^{28,116}$ The structure is similar to that of an ionomeric network where fatty acid chains are linked by the ester groups or metal carboxylates. These metal ions generally originate from fillers and pigments. With TOF-SIMS it is possible to locally characterize the different products formed during the drying of the oil. In the positive polarity, it is possible to differentiate whether the fatty acids are free or bound, and which bond is affected (ester or metal), whereas most of other analytical techniques can only obtain a mean value from these different cases. In 2005, Keune 
et al. published such an analysis of constituents from oils in cross-sections. ${ }^{37}$ Their conclusions are reported in Table 4. The fragment ions of fatty acids such as octanoic, nonanoic and decanoic acids (detected at $\mathrm{m} / \mathrm{z}$ 143.1, 157.1 and 171.1, respectively), provide additional chemical information about the polymerization of the oil, since they indicate a dried oil.

By extracting profiles along the depth of the painting, or along the cross-section, very useful information is obtained regarding the molecular changes during the drying of a paint layer, and changes in composition between the surface and the underlying layers can be observed. Free fatty acids are detected at the sample surface for fresh oils, but in underlying layers below the surface in aged oils, together with degradation products of triglycerides. The localization of metal soaps seems to be different than that of free fatty acids, and this may be due to an heterogeneity of the drying process or differential kinetics. ${ }^{37} \mathrm{~A}$ migration of triglycerides between layers has also been observed in multilayer systems such as painting cross sections, as well as a relative depletion in the top layers. ${ }^{107,117}$ The analysis of fatty acids by TOF-SIMS primarily involves the study of negative ions, formed mainly by breaking the ester bond of glycerol esters. Even if slight variations can occur, the desorption and ionization of the various mono-carboxylic fatty acids (palmitic and stearic) are comparable, which allows to study their relative intensities, as already discussed above, to help identifying the nature of the oil in individual layers of painting cross sections.

However, it has been shown that the concentrations of fatty acids and their relative distribution between and inside layers are altered by the mixing of binders (egg/oil mixture), interactions with the local environment (lead white pigment for instance), and aging processes that have taken place within the layers. The ratios may therefore no longer have the expected meaning. Moreover, these ratios will vary locally within the inhomogeneous layers themselves. Caution is therefore advised when using these ratios to identify the nature of an oil or egg yolk. On the other hand, the capacity of TOF-SIMS to spatially resolve the fatty acid ratios for each local environment allows one to characterize how the fatty acid concentration varies locally with the surrounding pigments and materials, in particular in altered areas like metallic soap aggregations. ${ }^{107}$

\section{Proteins}

Detecting and identifying proteins is of importance for diverse heritage samples, such as paintings or collagen and keratin containing materials like mummy remains or fossils. ${ }^{95,118}$ The analysis of proteins by TOF-SIMS imaging is hampered by the fact that only fragments of amino acids can be detected in a typical instrument (although intact peptides can be detected in some cases). ${ }^{119-121}$ Although it is easy to identify the presence of proteins in an image or in a spectrum thanks to marker ions common to all proteins $\left(\mathrm{CNO}^{-}\right.$or $\left.\mathrm{CNH}_{4}^{+}\right)$, the identification of a unique protein requires a thorough analysis of the detected fragments, in particular using multivariate analyses (Figure 7). ${ }^{122}$ The capabilities of TOF-SIMS to identify protein-based binders, namely glue and egg, was attested by comparison with Dot-ELISA. ${ }^{21}$ It was shown that the fragments of the hydroxyproline and leucine, which are detected at $\mathrm{m} / \mathrm{z} 86.06$ and 86.10, respectively, are characteristic of different animal glues in preparation layers. ${ }^{107}$ Because of 
interactions inside the sample as well as degradation effects, one needs to be cautious drawing conclusions based on the detection or absence of such fragments. ${ }^{123}$

\section{Tempera binder / egg yolk identification}

The blending of egg and oil in the same layer is scarcely mentioned in historical sources, and analytical difficulties are encountered in the effort to demonstrate the simultaneous presence of egg and oil, while excluding the possibility of contamination between layers. The detection of egg proteins and access to fatty acid ratios with separative quantitative methods such as GC-MS has proven to be a suitable approach, ${ }^{81}$ but complex paint layers are difficult to sample, and identifying both binders simultaneously does not indicate the spatial structure of the mixture. TOF-SIMS however allows one to image the micrometric structures within the layers after drying, so is an interesting tool to study tempera grassa. Its capacity to identify egg in binder mixtures was evaluated, using the detection and distribution of fatty acids. ${ }^{71}$ It appeared that evidences of egg yolk proteins, in particular in the case of egg/oil emulsion, were insufficient. Multivariate analysis has been shown to help identify amino acid fragments in order to distinguish between glues, yolk and egg white. ${ }^{117,124}$ In addition to amino acids fragments, phospholipid and cholesterol fragments are present in egg yolk and can be detected. Although these types of molecules are readily detected using TOF-SIMS, these molecules will likely have degraded in old painting samples and no longer produce the expected secondary ions. ${ }^{17}$ Some differences were also observed between the lipid fragment pattern of oil and egg, the fragments detected in egg yolk being relatively more saturated, with a higher proportion of oleic acid in egg yolk than in drying oils, and relatively less short chain fatty acids.

\section{Other observations}

The growing number of studies focusing on TOF-SIMS imaging of painting cross-sections allows for some miscellaneous observations to be made. The aforementioned correlation between the detection of fatty acids and lead compounds (in particular lead white grains), which could be linked with the structure of the ionomeric network, or the soap microstructures, seem to be a systematic observation. In addition to that, occurrences of chlorine being associated with lead white pigment and/or altered areas resulted in new hypotheses regarding its origin. It can be either from other pigments, the sea water added to the oil in some recipes or the manure used to manufacture lead white. The outer layers in cross section are usually more subjected to pollution, and TOF-SIMS is a valuable tool to analyze how the environment altered the object composition. ${ }^{125}$

\section{Conclusions}

The chemical analysis of old paintings has been of increasing interest for several decades. This review has shown the context and the objectives of the analysis of such samples by TOFSIMS imaging. TOF-SIMS imaging is unique for its capability to simultaneously detect and image inorganic and organic compounds at the surface of the sample, providing access to rich information on paint composition. The preparation of the samples and the complexity of the chemical interactions within the sample, together with matrix effects occurring during the 
secondary ion formation require further investigations, both on the analysis parameters and on the expected sample composition. However, TOF-SIMS imaging can already answer a number of questions, in particular with regard to oils and pigments. Certainly, there are limitations, especially due to the high rate of secondary ion fragmentation, which hampers the detection of large molecules like proteins. However, recent advances in instrumentation, both from the point of view of primary ion sources, as well as mass analyzers or data analysis, give hope that new answers can be provided with even more precision.

\section{References:}

[1] X. de Langlais. La Technique de La Peinture à l'huile; Flammarion: Paris, 1959.

[2] J. Dunkerton, M. Spring, R. Billinge, C. L. Higgitt, B. New, C. Campbell, D. A. Peggie, G. Macaro, R. Morrisson, R. Bellucci, J.-B. Bodiguel, C. Pasquali. National Gallery Technical Bulletin: Giovanni Bellini's Painting Technique., 39th ed.; National Gallery Company Ltd, 2018.

[3] L. Simonot. Etude Expérimentale et Modélisation de La Diffusion de La Lumière Dans Une Couche de Peinture Colorée et Translucide, Université Pierre et Marie Curie, 2003.

[4] I. Reiche. Mineral Pigments: The Colourful Palette of Nature. In European Mineralogical Union Notes in Mineralogy; 2019; Vol. 20, pp 283-322.

[5] H. Aldersey-Williams. Periodic Tales: The Curious Lives of the Elements; Penguin Books Limited, 2011.

[6] J. R. Barnett, S. Miller, E. Pearce. Colour and Art: A Brief History of Pigments. Opt. Laser Technol. 2006, 38, 445-453.

[7] R. Siddall. Mineral Pigments in Archaeology: Their Analysis and the Range of Available Materials. Minerals 2018, 8, 1-35.

[8] N. Eastaugh, V. Walsh, T. Chaplin, R. Siddall. Pigment Compendium A Dictionary and Optical Microscopy of Historical Pigments; 2008.

[9] Artists' Pigments A Handbook of Their History and Characteristics, Vol. 1; Feller, R. L., Ed.; National Gallery of Art, Washington, Archetype Publications, London, 1986.

[10] C. Cennini, G. Tambroni. Traité de La Peinture; Renouard, 1858.

[11] K. Keune, J. J. Boon. Analytical Imaging Studies Clarifying the Process of the Darkening of Vermilion in Paintings. Anal. Chem. 2005, 77, 4742-4750.

[12] V. Mazel, P. Richardin, D. Touboul, A. Brunelle, P. Walter, O. Laprévote. Chemical Imaging Techniques for the Analysis of Complex Mixtures: New Application to the Characterization of Ritual Matters on African Wooden Statuettes. Anal. Chim. Acta 2006, 570, 34-40.

[13] E. Pouyet, A. Lluveras-Tenorio, A. Nevin, D. Saviello, F. Sette, M. Cotte. Preparation of Thin-Sections of Painting Fragments: Classical and Innovative Strategies. Anal. Chim. Acta 2014, 822, 51-59.

[14] C. Higgitt, M. Spring, D. Saunders. Pigment-Medium Interactions in Oil Paint Films Containing Red Lead or Lead-Tin Yellow. Natl. Gall. Tech. Bull. 2003, 24, 75-95. 
[15] M. Cotte, E. Checroun, J. Susini, P. Dumas, P. Tchoreloff, M. Besnard, P. Walter. Kinetics of Oil Saponification by Lead Salts in Ancient Preparations of Pharmaceutical Lead Plasters and Painting Lead Mediums. Talanta 2006, 70, 1136-1142.

[16] N. Salvadó, S. Butí, J. Nicholson, H. Emerich, A. Labrador, T. Pradell. Identification of Reaction Compounds in Micrometric Layers from Gothic Paintings Using Combined SR-XRD and SR-FTIR. Talanta 2009, 79, 419-428.

[17] K. deGhetaldi. From Egg To Oil: The Early Development of Oil Painting During the Quattrocento, University of Delaware, 2016.

[18] R. White, J. Mills. Analyses of Paint Media. In National Gallery Technical Bulletin; 1977.

[19] E. Martin. Some Improvements in Techniques of Analysis of Paint Media. Stud. Conserv. 1977, 22, 63-67.

[20] H. Y. Lee, N. Atlasevich, C. Granzotto, J. Schultz, J. Loike, J. Arslanoglu. Development and Application of an ELISA Method for the Analysis of Protein-Based Binding Media of Artworks. Anal. Methods 2015, 7, 187-196.

[21] A. Atrei, F. Benetti, M. Potenza, L. Dei, E. Carretti, V. Niccolucci, N. Marchettini. Characterization of Organic Binders in a 13th Century Painted Wooden Panel: Comparison of ToF-SIMS and Dot-ELISA Results. Int. J. Mass Spectrom. 2018, 430, 63-68.

[22] M. Gambino, F. Cappitelli, C. Cattò, A. Carpen, P. Principi, L. Ghezzi, I. Bonaduce, E. Galano, P. Pucci, L. Birolo, F. Villa, F. Forlani. A Simple and Reliable Methodology to Detect Egg White in Art Samples. J. Biosci. 2013, 38, 397-408.

[23] L. S. Dolci, G. Sciutto, M. Guardigli, M. Rizzoli, S. Prati, R. Mazzeo, A. Roda. Ultrasensitive Chemiluminescent Immunochemical Identification and Localization of Protein Components in Painting Cross-Sections by Microscope Low-Light Imaging. Anal. Bioanal. Chem. 2008, 392, 29-35.

[24] S. Kuckova, I. C. A. Sandu, M. Crhova, R. Hynek, I. Fogas, S. Schafer. Protein Identification and Localization Using Mass Spectrometry and Staining Tests in CrossSections of Polychrome Samples. J. Cult. Herit. 2013, 14, 31-37.

[25] L. Cartechini, M. Vagnini, M. Palmieri, L. Pitzurra, T. Mello, J. Mazurek, G. Chiari. Immunodetection of Proteins in Ancient Paint Media. Acc. Chem. Res. 2010, 43, 867876.

[26] J. Arslanoglu, J. Schultz. Immunology and Art : Using Antibody-Based Techniques to Identify Proteins and Gums in Binding Media and Adhesives. Metrop. Museum Art Bull. 2009, 67, 40-45.

[27] I. C. A. Sandu, S. Schäfer, D. Magrini, S. Bracci, C. A. Roque. Cross-Section and Staining-Based Techniques for Investigating Organic Materials in Painted and Polychrome Works of Art: A Review. Microsc. Microanal. 2012, 18, 860-875.

[28] J. D. J. Van Den Berg. Analytical Chemical Studies on Traditional Linseed Oil Paints; 2002.

[29] C. D. Calvano, I. D. Van Der Werf, F. Palmisano, L. Sabbatini. Fingerprinting of Egg and Oil Binders in Painted Artworks by Matrix-Assisted Laser Desorption Ionization 
Time-of-Flight Mass Spectrometry Analysis of Lipid Oxidation by-Products. Anal. Bioanal. Chem. 2011, 400, 2229-2240.

[30] S. Kuckova, R. Hynek, M. Kodicek. MALDI-MS Applied to the Analysis of Protein Paint Binders. In Organic Mass Spectrometry in Art and Archaeology; Colombini, M. P., Modugno, F., Eds.; John Wiley \& Sons, 2009; pp 165-187.

[31] M. P. Colombini, F. Modugno, G. Giorgi. Organic Materials in Art and Archaeology. Organic Mass Spectrometry in Art and Archaeology. August 2009, pp 1-36.

[32] I. Bonaduce, M. Cito, M. P. Colombini. The Development of a Gas ChromatographicMass Spectrometric Analytical Procedure for the Determination of Lipids, Proteins and Resins in the Same Paint Micro-Sample Avoiding Interferences from Inorganic Media. J. Chromatogr. A 2009, 1216, 5931-5939.

[33] M. Hochmann. Colorito, La Technique Des Peintres Vénitiens à La Renaissance; 2015.

[34] M. Cotte, E. Checroun, W. De Nolf, Y. Taniguchi, L. De Viguerie, M. Burghammer, P. Walter, C. Rivard, M. Salomé, K. Janssens, J. Susini. Lead Soaps in Paintings: Friends or Foes? Stud. Conserv. 2017, 62, 2-23.

[35] Metal Soaps in Art, Cultural H.; Casadio, F., Keune, K., Noble, P., Van Loon, A., Hendriks, E., Centeno, S. A., Osmond, G., Eds.; Springer, 2019.

[36] M. Cotte, E. Checroun, J. Susini, P. Walter. Micro-Analytical Study of Interactions between Oil and Lead Compounds in Paintings. Appl. Phys. A Mater. Sci. Process. 2007, 89, 841-848.

[37] K. Keune, E. S. B. Ferreira, J. J. Boon. Characterization and Localization of the OilBinding Medium in Paint Cross-Sections Using Imaging Secondary Ion Mass Spectrometry. Trienn. Meet. (14th), Hague, 12-16 Sept. 2005 Prepr. 2005, 796-802.

[38] Y. C. K. Chen-Wiegart, J. Catalano, G. J. Williams, A. Murphy, Y. Yao, N. Zumbulyadis, S. A. Centeno, C. Dybowski, J. Thieme. Elemental and Molecular Segregation in Oil Paintings Due to Lead Soap Degradation. Sci. Rep. 2017, 7.

[39] R. Castaing, G. Slodzian. Microanalyse Par Émission Ionique Secondaire. Journal of Microscopy. J. Microsc. 1962, 1, 395-410.

[40] A. Benninghoven. Surface Investigation of Solids by the Statical Method of Secondary Ion Mass Spectroscopy (SIMS). Surf. Sci. 1973, 35, 427-457.

[41] B. T. Chait, K. G. Standing. A Time-of-Flight Mass Spectrometer for Measurement of Secondary Ion Mass Spectra. Int. J. Mass Spectrom. Ion Phys. 1981, 40, 185-193.

[42] J. C. Vickerman, D. Briggs. ToF-SIMS: Materials Analysis by Mass Spectrometry; SurfaceSpectra, 2013.

[43] P. van der Heide. Secondary Ion Mass Spectrometry; Wiley Online Books; John Wiley \& Sons, Inc.: Hoboken, NJ, USA, 2014.

[44] P. Sudraud, J. Van De Walle, C. Colliex, R. Castaing. Contribution of Field Effects to the Achievement of Higher Brightness Ion Sources. Surf. Sci. 1978, 70, 392-402.

[45] P. K. Rol, J. M. Fluit, J. Kistemaker. Sputtering of Copper by Bombardment with Ions of 5-25 KeV. Physica 1960, 26, 1000-1008. 
[46] H. H. Andersen, H. L. Bay. Nonlinear Effects in Heavy-ion Sputtering. J. Appl. Phys. 1974, 45, 953-954.

[47] M. Benguerba, A. Brunelle, S. Della-Negra, J. Depauw, H. Joret, Y. Le Beyec, M. G. Blain, E. A. Schweikert, G. Ben Assayag, P. Sudraud. Impact of Slow Gold Clusters on Various Solids: Nonlinear Effects in Secondary Ion Emission. Nucl. Instrum. Methods Phys. Res. B 1991, 62, 8-22.

[48] A. Brunelle, S. Della-Negra, J. Depauw, D. Jacquet, Y. Le Beyec, M. Pautrat, K. Baudin, H. H. Andersen. Enhanced Secondary-Ion Emission under Gold-Cluster Bombardment with Energies from $\mathrm{KeV}$ to MeV per Atom. Phys. Rev. A 2001, 63.

[49] H. H. Andersen, A. Brunelle, S. Della-Negra, J. Depauw, D. Jacquet, Y. Le Beyec, J. Chaumont, H. Bernas. Giant Metal Sputtering Yields Induced by 20-5000 KeV/Atom Gold Clusters. Phys. Rev. Lett. 1998, 80, 5433-5436.

[50] N. Wehbe, M. Fallavier, S. Della Negra, J. Depauw, A. Brunelle, H. H. Andersen. Cluster Size and Velocity Dependences of Sputtering and Secondary Ion Emission under Gold Cluster Impact. Nucl. Instrum. Methods Phys. Res. B 2010, 268, 25962602.

[51] K. Boussofiane-Baudin, G. Bolbach, A. Brunelle, S. Della-Negra, P. Håkansson, Y. Le Beyec. Secondary Ion Emission under Cluster Impact at Low Energies (5-60 KeV); Influence of the Number of Atoms in the Projectile. Nucl. Instrum. Methods Phys. Res. B 1994, 88, 160-163.

[52] A. Brunelle, S. Della-Negra. Trends to a Semi-Empirical Model for Cluster Induced Metal Sputtering. Nucl. Instrum. Methods Phys. Res. B 2004, 222, 68-74.

[53] N. Davies, D. E. Weibel, P. Blenkinsopp, N. Lockyer, R. Hill, J. C. Vickerman. Development and Experimental Application of a Gold Liquid Metal Ion Source. Appl. Surf. Sci. 2003, 203-204, 223-227.

[54] D. Touboul, F. Halgand, A. Brunelle, R. Kersting, E. Tallarek, B. Hagenhoff, O. Laprévote. Tissue Molecular Ion Imaging by Gold Cluster Ion Bombardment. Anal. Chem. 2004, 76, 1550-1559.

[55] P. Sjövall, J. Lausmaa, B. Johansson. Mass Spectrometric Imaging of Lipids in Brain Tissue. Anal. Chem. 2004, 76, 4271-4278.

[56] A. Brunelle, D. Touboul, O. Laprévote. Biological Tissue Imaging with Time-of-Flight Secondary Ion Mass Spectrometry and Cluster Ion Sources. J. Mass Spectrom. 2005, 40, 985-999.

[57] D. Touboul, F. Kollmer, E. Niehuis, A. Brunelle, O. Laprévote. Improvement of Biological Time-of-Flight-Secondary Ion Mass Spectrometry Imaging with a Bismuth Cluster Ion Source. J. Am. Soc. Mass Spectrom. 2005, 16, 1608-1618.

[58] D. Weibel, S. Wong, N. Lockyer, P. Blenkinsopp, R. Hill, J. C. Vickerman. A C60 Primary Ion Beam System for Time of Flight Secondary Ion Mass Spectrometry: Its Development and Secondary Ion Yield Characteristics. Anal. Chem. 2003, 75, 17541764.

[59] S. Ninomiya, Y. Nakata, Y. Honda, K. Ichiki, T. Seki, T. Aoki, J. Matsuo. A FragmentFree Ionization Technique for Organic Mass Spectrometry with Large Ar Cluster Ions. Appl. Surf. Sci. 2008, 255, 1588-1590. 
[60] C. Bich, R. Havelund, R. Moellers, D. Touboul, F. Kollmer, E. Niehuis, I. S. Gilmore, A. Brunelle. Argon Cluster Ion Source Evaluation on Lipid Standards and Rat Brain Tissue Samples. Anal. Chem. 2013, 85, 7745-7752.

[61] T. Péresse, N. Elie, D. Touboul, V. C. Pham, V. Dumontet, F. Roussi, M. Litaudon, A. Brunelle. Dual Beam Depth Profiling and Imaging with Argon and Bismuth Clusters of Prenylated Stilbenes on Glandular Trichomes of Macaranga Vedeliana. Anal. Chem. 2017, 89, 9247-9252.

[62] V. Gabelica, E. De Pauw. Internal Energy and Fragmentation of Ions Produced in Electrospray Sources. Mass Spectrom. Rev. 2005, 24, 566-587.

[63] T. Fu, S. Della-Negra, D. Touboul, A. Brunelle. Internal Energy Distribution of Secondary Ions Under Argon and Bismuth Cluster Bombardments: "Soft" Versus "Hard” Desorption-Ionization Process. J. Am. Soc. Mass Spectrom. 2019, 30, 321-328.

[64] R. N. S. Sodhi. Time-of-Flight Secondary Ion Mass Spectrometry (TOF-SIMS):Versatility in Chemical and Imaging Surface Analysis. Analyst 2004, 129, 483-487.

[65] Q. P. Vanbellingen, N. Elie, M. J. Eller, S. Della-Negra, D. Touboul, A. Brunelle. Time-of-Flight Secondary Ion Mass Spectrometry Imaging of Biological Samples with Delayed Extraction for High Mass and High Spatial Resolutions. Rapid Commun. Mass Spectrom. 2015, 29, 1187-1195.

[66] B. A. Mamyrin, V. I. Karataev, D. V Shmikk, V. A. Zagulin. The Mass-Reflectron, a New Nonmagnetic Time-of-Flight Mass Spectrometer with High Resolution. Sov. Phys. JETP 1973, 37, 45-48.

[67] R. J. Cotter. Time-of-Flight Mass Spectrometry. Instrumentation and Applications in Biological Research; American Chemical Society, Ed.; Washington, DC, 1997.

[68] R. Van Ham, L. Van Vaeck, F. Adams, A. Adriaens. Feasibility of Analyzing Molecular Pigments in Paint Layers Using TOF S-SIMS. Anal. Bioanal. Chem. 2005, 383, 991-997.

[69] A. Seyer, J. Einhorn, A. Brunelle, O. Laprévote. Localization of Flavonoids in Seeds by Cluster Time-of-Flight Secondary Ion Mass Spectrometry Imaging. Anal. Chem. 2010, 82, 2326-2333.

[70] C. Bouvier, H. Glanville, L. De Viguerie, C. Merucci, P. Walter, A. Brunelle. Time-ofFlight Secondary Ion Mass Spectrometry Imaging of Cross Sections from the Bacchanals Paintings of Nicolas Poussin. Anal. Chem. 2021, 93, 4463-4471.

[71] K. Keune, J. J. Boon. Imaging Secondary Ion Mass Spectrometry of a Paint Cross Section Taken from an Early Netherlandish Painting by Rogier van Der Weyden. Anal. Chem. 2004, 76, 1374-1385.

[72] K. Keune, J. J. Boon. Enhancement of the Static SIMS Secondary Ion Yields of Lipid Moieties by Ultrathin Gold Coating of Aged Oil Paint Surfaces. Surf. Interface Anal. 2004, 36, 1620-1628.

[73] T. Fu, N. Elie, A. Brunelle. Radial Distribution of Wood Extractives in European Larch Larix Decidua by TOF-SIMS Imaging. Phytochemistry 2018, 150, 31-39.

[74] Q. P. Vanbellingen, T. Fu, C. Bich, N. Amusant, D. Stien, S. Della-Negra, D. Touboul, A. Brunelle. Mapping Dicorynia Guianensis Amsh. Wood Constituents by Submicron 
Resolution Cluster-TOF-SIMS Imaging. J. Mass Spectrom. 2016, 51, 412-423.

[75] M. K. Passarelli, C. F. Newman, P. S. Marshall, A. West, I. S. Gilmore, J. Bunch, M. R. Alexander, C. T. Dollery. Single-Cell Analysis: Visualizing Pharmaceutical and Metabolite Uptake in Cells with Label-Free 3D Mass Spectrometry Imaging. Anal. Chem. 2015, 87, 6696-6702.

[76] S. Van Nuffel, M. Quatredeniers, A. Pirkl, J. Zakel, J. P. Le Caer, N. Elie, Q. P. Vanbellingen, S. J. Dumas, M. K. Nakhleh, M. R. Ghigna, E. Fadel, M. Humbert, P. Chaurand, D. Touboul, S. Cohen-Kaminsky, A. Brunelle. Multimodal Imaging Mass Spectrometry to Identify Markers of Pulmonary Arterial Hypertension in Human Lung Tissue Using MALDI-ToF, ToF-SIMS, and Hybrid SIMS. Anal. Chem. 2020, 92, 12079-12087.

[77] Q. P. Vanbellingen, A. Castellanos, M. Rodriguez-Silva, I. Paudel, J. W. Chambers, F. A. Fernandez-Lima. Analysis of Chemotherapeutic Drug Delivery at the Single Cell Level Using 3D-MSI-TOF-SIMS. J. Am. Soc. Mass Spectrom. 2016, 27, 2033-2040.

[78] S. Van Nuffel, N. Elie, E. Yang, J. Nouet, D. Touboul, P. Chaurand, A. Brunelle. Insights into the MALDI Process after Matrix Deposition by Sublimation Using 3D ToF-SIMS Imaging. Anal. Chem. 2018, 90, 1907-1914.

[79] P. Sjövall, B. Johansson, J. Lausmaa. Localization of Lipids in Freeze-Dried Mouse Brain Sections by Imaging TOF-SIMS. Appl. Surf. Sci. 2006, 252, 6966-6974.

[80] E. A. Jones, N. P. Lockyer, J. C. Vickerman. Mass Spectral Analysis and Imaging of Tissue by ToF-SIMS-The Role of Buckminsterfullerene, C60+, Primary Ions. Int. J. Mass Spectrom. 2007, 260, 146-157.

[81] K. B. Kalinina, I. Bonaduce, M. P. Colombini, I. S. Artemieva. An Analytical Investigation of the Painting Technique of Italian Renaissance Master Lorenzo Lotto. $J$. Cult. Herit. 2012, 13, 259-274.

[82] C. Bich, D. Touboul, A. Brunelle. Study of Experimental Variability in TOF-SIMS Mass Spectrometry Imaging of Biological Samples. Int. J. Mass Spectrom. 2013, 337, 43-49.

[83] G. L. Fisher, J. S. Hammond, P. E. Larson, S. R. Bryan, R. M. A. Heeren. Parallel Imaging MS/MS TOF-SIMS Instrument. J. Vac. Sci. Technol. B 2016, 34, 03 H126.

[84] T. Fu, D. Touboul, S. Della-Negra, E. Houël, N. Amusant, C. Duplais, G. L. Fisher, A. Brunelle. Tandem Mass Spectrometry Imaging and in Situ Characterization of Bioactive Wood Metabolites in Amazonian Tree Species Sextonia Rubra. Anal. Chem. 2018, 90, 7535-7543.

[85] T. Fu, E. Houël, N. Amusant, D. Touboul, G. Genta-Jouve, S. Della-Negra, G. L. Fisher, A. Brunelle, C. Duplais. Biosynthetic Investigation of $\gamma$-Lactones in Sextonia Rubra Wood Using in Situ TOF-SIMS MS/MS Imaging to Localize and Characterize Biosynthetic Intermediates. Sci. Rep. 2019, 9, 1928.

[86] J. S. Fletcher, S. Rabbani, A. Henderson, P. Blenkinsopp, S. P. Thompson, N. P. Lockyer, J. C. Vickerman. A New Dynamic in Mass Spectral Imaging of Single Biological Cells. Anal. Chem. 2008, 80, 9058-9064.

[87] S. Sheraz Née Rabbani, I. B. Razo, T. Kohn, N. P. Lockyer, J. C. Vickerman. Enhancing Ion Yields in Time-of-Flight-Secondary Ion Mass Spectrometry: A 
Comparative Study of Argon and Water Cluster Primary Beams. Anal. Chem. 2015, 87, 2367-2374.

[88] M. K. Passarelli, A. Pirkl, R. Moellers, D. Grinfeld, F. Kollmer, R. Havelund, C. F. Newman, P. S. Marshall, H. Arlinghaus, M. R. Alexander, A. West, S. Horning, E. Niehuis, A. Makarov, C. T. Dollery, I. S. Gilmore. The 3D OrbiSIMS-Label-Free Metabolic Imaging with Subcellular Lateral Resolution and High Mass-Resolving Power. Nat. Methods 2017, 14, 1175-1183.

[89] D. Debois, M. P. Bralet, F. Le Naour, A. Brunelle, O. Laprévote. In Situ Lipidomic Analysis of Nonalcoholic Fatty Liver by Cluster TOF-SIMS Imaging. Anal. Chem. 2009, 81, 2823-2831.

[90] S. Solé-Domènech, P. Sjövall, V. Vukojević, R. Fernando, A. Codita, S. Salve, N. Bogdanović, A. H. Mohammed, P. Hammarström, K. P. R. Nilsson, F. M. Laferla, S. Jacob, P. O. Berggren, L. Giménez-Llort, M. Schalling, L. Terenius, B. Johansson. Localization of Cholesterol, Amyloid and Glia in Alzheimer's Disease Transgenic Mouse Brain Tissue Using Time-of-Flight Secondary Ion Mass Spectrometry (ToFSIMS) and Immunofluorescence Imaging. Acta Neuropathol. 2013, 125, 145-157.

[91] A. N. Lazar, C. Bich, M. Panchal, N. Desbenoit, V. W. Petit, D. Touboul, L. Dauphinot, C. Marquer, O. Laprevote, A. Brunelle, C. Duyckaerts. Time-of-Flight Secondary Ion Mass Spectrometry (TOF-SIMS) Imaging Reveals Cholesterol Overload in the Cerebral Cortex of Alzheimer Disease Patients. Acta Neuropathol. 2013, 125, $133-144$

[92] J. Lee, T. Terlier, Y. J. Jang, K. B. Lee, Y. Lee. Structural Colors and Physical Properties of Elytra in the Jewel Beetle, Chrysochroa Fulgidissima, Using Surface Analytical Techniques. Surf. Interface Anal. 2020, 52, 656-664.

[93] R. E. Goacher, D. Jeremic, E. R. Master. Expanding the Library of Secondary Ions That Distinguish Lignin and Polysaccharides in Time-of-Flight Secondary Ion Mass Spectrometry Analysis of Wood. Anal. Chem. 2011, 83, 804-812.

[94] Y. Dauphin, A. Brunelle, M. Cotte, J. P. Cuif, B. Farre, O. Laprevote, A. Meibom, M. Salome, C. T. Williams. A Layered Structure in the Organic Envelopes of the Prismatic Layer of the Shell of the Pearl Oyster Pinctada Margaritifera (Mollusca, Bivalvia). Microsc. Microanal. 2010, 16, 91-98.

[95] S. Bertazzo, S. C. R. Maidment, C. Kallepitis, S. Fearn, M. M. Stevens, H. N. Xie. Fibres and Cellular Structures Preserved in 75-Million-Year-Old Dinosaur Specimens. Nat. Commun. 2015, 6, 7352:1-8.

[96] B. Ménez, C. Pisapia, M. Andreani, F. Jamme, Q. P. Vanbellingen, A. Brunelle, L. Richard, P. Dumas, M. Réfrégiers. Abiotic Synthesis of Amino Acids in the Recesses of the Oceanic Lithosphere. Nature 2018, 564, 59-63.

[97] J. Lindgren, P. Uvdal, P. Sjövall, D. E. Nilsson, A. Engdahl, B. P. Schultz, V. Thiel. Molecular Preservation of the Pigment Melanin in Fossil Melanosomes. Nat. Commun. 2012, 3, 824:1-7.

[98] S. Muramoto, T. P. Forbes, A. C. Van Asten, G. Gillen. Test Sample for the Spatially Resolved Quantification of Illicit Drugs on Fingerprints Using Imaging Mass Spectrometry. Anal. Chem. 2015, 87, 5444-5450. 
[99] A. Bejjani, M. Noun, S. Della-Negra, R. Tannous, G. Chalhoub, M. Hamdan, B. Nsouli. Topography Measurements Using High Mass Resolution Time-of-Flight Secondary Ion Mass Spectrometry: Application to Banknotes. Anal. Chem. 2019, 91, 8864-8872.

[100] A. Adriaens, M. G. Dowsett. Applications of SIMS to Cultural Heritage Studies. Appl. Surf. Sci. 2006, 252, 7096-7101.

[101] V. Mazel, P. Richardin, D. Touboul, A. Brunelle, C. Richard, E. Laval, P. Walter, O. Laprévote. Animal Urine as Painting Materials in African Rock Art Revealed by Cluster ToF-SIMS Mass Spectrometry Imaging. J. Mass Spectrom. 2010, 45, 944-950.

[102] V. Mazel, P. Richardin, D. Debois, D. Touboul, M. Cotte, A. Brunelle, P. Walter, O. Laprévote. Identification of Ritual Blood in African Artifacts Using TOF-SIMS and Synchrotron Radiation Microspectroscopies. Anal. Chem. 2007, 79, 9253-9260.

[103] V. Mazel, P. Richardin, D. Debois, D. Touboul, M. Cotte, A. Brunelle, P. Walter, O. Laprévote. The Patinas of the Dogon-Tellem Statuary: A New Vision through PhysicoChemical Analyses. J. Cult. Herit. 2008, 9, 347-353.

[104] O. D. Sanni, M. S. Wagner, D. Briggs, D. G. Castner, J. C. Vickerman. Classification of Adsorbed Protein Static ToF-SIMS Spectra by Principal Component Analysis and Neural Networks. Surf. Interface Anal. 2002, 33, 715-728.

[105] J. J. Boon, K. Keune, J. Van Der Weerd, M. Geldof, J. R. J. Van Asperen De Boer. Imaging Microspectroscopic Secondary Ion Mass Spectrometric and Electron Microscopic Studies on Discoloured and Partially Discoloured Smalt in Cross-Sections of 16th Century Paintings. Chimia (Aarau). 2001, 55, 952-960.

[106] P. Richardin, V. Mazel, P. Walter, O. Laprévote, A. Brunelle. Identification of Different Copper Green Pigments in Renaissance Paintings by Cluster-TOF-SIMS Imaging Analysis. J. Am. Soc. Mass Spectrom. 2011, 22, 1729-1736.

[107] M. Noun, E. Van Elslande, D. Touboul, H. Glanville, S. Bucklow, P. Walter, A. Brunelle. High Mass and Spatial Resolution Mass Spectrometry Imaging of Nicolas Poussin Painting Cross Section by Cluster TOF-SIMS. J. Mass Spectrom. 2016, 51, 1196-1210.

[108] J. Sanyova, S. Cersoy, P. Richardin, O. Laprevote, P. Walter, A. Brunelle. Unexpected Materials in a Rembrandt Painting Characterized by High Spatial Resolution ClusterTOF-SIMS Imaging. Anal. Chem. 2011, 83, 753-760.

[109] E. P. van Dam, K. J. van den Berg, A. N. Proaño Gaibor, M. van Bommel. Analysis of Triglyceride Degradation Products in Drying Oils and Oil Paints Using LC-ESI-MS. Int. J. Mass Spectrom. 2017, 413, 33-42.

[110] M. J. Taylor, K. Y. Zhang, D. J. Graham, L. J. Gamble. Fatty Acid and Lipid Reference Spectra. Surf. Sci. Spectra 2018, 25, 025001.

[111] D. Gode, D. A. Volmer. Lipid Imaging by Mass Spectrometry-a Review. Analyst 2013, $138,1289-1315$.

[112] M. R. Schilling, H. P. Khanjian. ICOM Commitee for Conservation. 1996, 1.

[113] J. S. Mills. The Gas Chromatographic Examination of Paint Media. Part 1. Fatty Acid Composition and Identification of Dried Oil Films. Stud. Conserv. 1966, 11, 92-107. 
[114] M. P. Colombini, F. Modugno, R. Fuoco, A. Tognazzi. A GC-MS Study on the Deterioration of Lipidic Paint Binders. Microchem. J. 2002, 73, 175-185.

[115] M. P. Colombini, F. Modugno, E. Menicagli, R. Fuoco, A. Giacomelli. GC-MS Characterization of Proteinaceous and Lipid Binders in UV Aged Polychrome Artifacts. Microchem. J. 2000, 67, 291-300.

[116] T. M. Grehk, R. Berger, U. Bexell. Investigation of the Drying Process of Linseed Oil Using FTIR and ToF-SIMS. J. Phys. Conf. Ser. 2008, 100, 1-4.

[117] Z. E. Voras, K. deGhetaldi, B. Baade, E. Gordon, G. Gates, T. P. Beebe. Comparison of Oil and Egg Tempera Paint Systems Using Time-of-Flight Secondary Ion Mass Spectrometry. Stud. Conserv. 2016, 61, 222-235.

[118] S. Cersoy, P. Richardin, P. Walter, A. Brunelle. Cluster TOF-SIMS Imaging of Human Skin Remains: Analysis of a South-Andean Mummy Sample. J. Mass Spectrom. 2012, 47, 338-346.

[119] A. Brunelle, S. Della-Negra, C. Deprun, J. Depauw, P. Håkansson, D. Jacquet, Y. Le Beyec, M. Pautrat. High Desorption-Ionization Yields of Large Biomolecules Induced by Fast C60 Projectiles. Int. J. Mass Spectrom. Ion Process. 1997, 164, 193-200.

[120] N. Ogrinc Potočnik, G. L. Fisher, A. Prop, R. M. A. Heeren. Sequencing and Identification of Endogenous Neuropeptides with Matrix-Enhanced Secondary Ion Mass Spectrometry Tandem Mass Spectrometry. Anal. Chem. 2017, 89, 8223-8227.

[121] A. M. Kotowska, G. F. Trindade, P. M. Mendes, P. M. Williams, J. W. Aylott, A. G. Shard, M. R. Alexander, D. J. Scurr. Protein Identification by 3D OrbiSIMS to Facilitate in Situ Imaging and Depth Profiling. Nat. Commun. 2020, 11, 1-8.

[122] F. Benetti, G. Perra, D. Damiani, A. Atrei, N. Marchettini. ToF-SIMS Characterization of Proteinaceous Binders in the Wall Painting "Madonna and Child Enthroned with Saints" by Ambrogio Lorenzetti in the St. Augustine Church (Siena, Italy). Int. J. Mass Spectrom. 2015, 392, 111-117.

[123] G. Gautier, M. P. Colombini. GC-MS Identification of Proteins in Wall Painting Samples: A Fast Clean-up Procedure to Remove Copper-Based Pigment Interferences. Talanta 2007, 73, 95-102.

[124] A. Atrei, F. Benetti, E. Gliozzo, G. Perra, N. Marchettini. Chemical Characterization of Protein Based Binders in Painting Samples by Means of ToF-SIMS: Tests on Ancient and Model Samples. Int. J. Mass Spectrom. 2014, 369, 9-15.

[125] M. Melcher, R. Wiesinger, M. Schreiner. Degradation of Glass Artifacts: Application of Modern Surface Analytical Techniques. Acc. Chem. Res. 2010, 43, 916-926.

[126] M. Cotte, E. Checroun, V. Mazel, V. A. Solé, P. Richardin, Y. Taniguchi, P. Walter, J. Susini. Combination of FTIR and X-Rays Synchrotron-Based Micro-Imaging Techniques for the Study of Ancient Paintings: A Practical Point of View. $e$ Preservation Sci. 2009, 6, 1-9.

[127] J. van der Weerd, A. van Loon, J. J. Boon. FTIR Studies of the Effects of Pigments on the Aging of Oil. Stud. Conserv. 2005, 50, 3-22.

[128] L. Robinet, M. Spring, S. Pagès-Camagna. Vibrational Spectroscopy Correlated with Elemental Analysis for the Investigation of Smalt Pigment and Its Alteration in 
Paintings. Anal. Methods 2013, 5, 4628-4638.

[129] M. L. Amadori, S. Barcelli, G. Poldi, F. Ferrucci, A. Andreotti, P. Baraldi, M. P. Colombini. Invasive and Non-Invasive Analyses for Knowledge and Conservation of Roman Wall Paintings of the Villa of the Papyri in Herculaneum. Microchem. J. 2014, $118,183-192$.

[130] V. Otero, D. Sanches, C. Montagner, M. Vilarigues, L. Carlyle, J. A. Lopes, M. J. Melo. Characterisation of Metal Carboxylates by Raman and Infrared Spectroscopy in Works of Art. J. Raman Spectrosc. 2014, 45, 1197-1206.

[131] M. Alfeld, L. de Viguerie. Recent Developments in Spectroscopic Imaging Techniques for Historical Paintings - A Review. Spectrochim. Acta - Part B At. Spectrosc. 2017, $136,81-105$.

[132] A. Burnstock, C. Jones. Scanning Electron Microscopy Techniques for Imaging Materials from Paintings. In Radiation in Art and Archeometry; Elsevier, 2000; pp $202-231$.

[133] A. Fanost, A. Gimat, L. de Viguerie, P. Martinetto, A. C. Giot, M. Clémancey, G. Blondin, F. Gaslain, H. Glanville, P. Walter, G. Mériguet, A. L. Rollet, M. Jaber. Revisiting the Identification of Commercial and Historical Green Earth Pigments. Colloids Surfaces A Physicochem. Eng. Asp. 2020, 584, 124035.

[134] L. De Viguerie, P. Walter, E. Laval, B. Mottin, V. A. Solé. Revealing the Sfumato Technique of Leonardo Da Vinci by X-Ray Fluorescence Spectroscopy. Angew. Chemie - Int. Ed. 2010, 49, 6125-6128. 
Table 1: Techniques used for the analysis of cultural heritage samples

\begin{tabular}{|c|c|c|c|c|c|c|c|}
\hline \multirow[b]{3}{*}{ Technique } & \multicolumn{7}{|c|}{ Features } \\
\hline & \multicolumn{2}{|c|}{ Imaging } & \multicolumn{2}{|c|}{ Provided data } & \multirow[b]{2}{*}{ Invasive } & \multirow[b]{2}{*}{ Destructive } & \multirow[b]{2}{*}{$\begin{array}{l}\text { Examples on cultural heritage } \\
\text { samples }\end{array}$} \\
\hline & Locally & $\begin{array}{c}\text { Over } \\
\text { large } \\
\text { surfaces }\end{array}$ & Organic & Inorganic & & & \\
\hline FTIR & $\mathrm{x}$ & & $\mathrm{x}$ & $\mathrm{x}$ & $\mathrm{x}$ & & 126,127 \\
\hline Raman & $\mathrm{x}$ & & $\mathrm{x}$ & $\mathrm{x}$ & $\mathrm{x}$ & & 128129,130 \\
\hline SWIR & $\mathrm{x}$ & $x$ & $\mathrm{x}$ & $\mathrm{x}$ & & & 131 \\
\hline SEM & $\mathrm{x}$ & & & $\mathrm{x}$ & $\mathrm{x}$ & & 132 \\
\hline$\mu-X R D$ & & $\mathrm{x}$ & & $\mathrm{x}$ & & & 133 \\
\hline XRF & $\mathrm{x}$ & $\mathrm{x}$ & & $\mathrm{x}$ & & & 134 \\
\hline GC-MS & & & $\mathrm{x}$ & $\mathrm{x}$ & $\mathrm{x}$ & $\mathrm{x}$ & 31,32 \\
\hline TOF-SIMS & $\mathrm{x}$ & & $\mathrm{x}$ & $\mathrm{x}$ & $\mathrm{x}$ & & $70,102,107,108$ \\
\hline
\end{tabular}

Table 2: Comparison between different mass spectrometry imaging methods

\begin{tabular}{|c|c|c|c|c|c|c|}
\hline Technique & $\begin{array}{l}\text { Lateral } \\
\text { resolution } \\
(\mu \mathrm{m})\end{array}$ & $\begin{array}{c}\text { Sample } \\
\text { preparation }\end{array}$ & $\begin{array}{c}\text { Sample } \\
\text { destruction? }\end{array}$ & $\begin{array}{l}\text { Mass range } \\
\text { (Da) }\end{array}$ & Protein analysis & Inorganic analysis \\
\hline TOF-SIMS & $0.4-1$ & $\begin{array}{l}\text { Flat and clean } \\
\text { surface }\end{array}$ & $\begin{array}{l}\text { Negligible, only } \\
\text { at nanometric } \\
\text { scale }\end{array}$ & $<1,000$ & Amino-acid fragments & Yes \\
\hline MALDI-TOF & $\approx 10$ & Matrix coating & $\begin{array}{l}\text { Yes (sample is } \\
\text { fixed by the } \\
\text { matrix) }\end{array}$ & $\sim 10,000$ & Yes & No \\
\hline LA-ICP-MS & $5-200$ & $\begin{array}{l}\text { Flat and clean } \\
\text { surface }\end{array}$ & Yes (ablation) & - & Yes if tagged & $\begin{array}{c}\text { Yes, with } \\
\text { quantification }\end{array}$ \\
\hline Nano-SIMS & $0.05-0.15$ & $\begin{array}{c}\text { Flat and } \\
\text { conductive } \\
\text { surface }\end{array}$ & Negligible & - & Yes if tagged & Yes \\
\hline DESI & $\approx 100$ & Minimal, $\mathrm{P}_{\text {atm }}$ & Negligible & $\sim 5,000$ & Yes & No \\
\hline
\end{tabular}

Table 3: Lipid ions which are detected in the presence of an oil binder in positive and negative ion modes (M is the lipid molecule

\begin{tabular}{ccc}
\hline & Negative ions & Positive ions \\
\hline Fatty acid & {$[\mathrm{M}-\mathrm{H}]^{-}$} & {$[\mathrm{M}+\mathrm{H}]^{+}$, acylium $[\mathrm{M}-\mathrm{OH}]^{+}$} \\
Di -,Tri-glycerides & - & Fragments $\left[\mathrm{M}-\mathrm{H}_{2} \mathrm{O}+\mathrm{H}\right]^{+},[\mathrm{M}+\mathrm{Na}]^{+}$ \\
\hline
\end{tabular}

Table 4 : Relation between the detected ion and the local composition in oil layers with lead ${ }^{37}$

\begin{tabular}{lllc}
\hline \multicolumn{1}{c}{ Type of fatty acid } & Detected ion species & Proportion \\
\hline \multirow{2}{*}{ Free fatty acid } & Protonated molecule & $(\mathbf{M + H})^{+}$ & $\approx 55 \%$ \\
& Acylium ion & $(\mathbf{M}-\mathbf{O H})^{+}$ & $\approx 45 \%$ \\
\hline \multirow{2}{*}{ Linked to an ester } & Acylium ion & $(\mathbf{M}-\mathbf{O H})^{+}$ & $\approx 100 \%$ \\
\hline \multirow{2}{*}{ Linked to a metal } & Molecule cationized with the metal & $(\mathbf{M + m})^{+}$ & Intense \\
& Protonated molecule & $(\mathbf{M}+\mathbf{H})^{+}$ & Weak \\
\hline
\end{tabular}




\section{Figure captions}

Figure 1 Schematic view of a painting cross-section with the common layers

Figure 2 a. Infant Bacchanals painting, Nicolas Poussin (Les Andelys, France, 1594 Rome, 1665), painted around 1626, National Gallery of Ancient Art, Palazzo Barberini, Rome, Italy, $56 \mathrm{~cm} \times 76 \mathrm{~cm}$ (photograph copyright A. Brunelle and courtesy of the Museo Nazionale d'Arte Antica). Schematic view of a scalpel at the point of sampling the cross-section. b. Microscope top view of the crosssection embedded in resin. Scale bar $100 \mu \mathrm{m}$, and schematic view of the sample embedded in resin. C; Schematic top view of the cross-section with annotated layers. Adapted from reference ${ }^{70}$

Figure 3 Schematic of the most commonly used binders in paintings according to their chemical composition

Figure 4 Painted stone: ToF-SIMS negative and positive ion images of the cross-section of the white pigment. Dimension of images $500 \mu \mathrm{m} \times 500 \mu \mathrm{m}$. From reference ${ }^{101}$ Copyright (C) 2010 John Wiley \& Sons, Ltd.

Figure 5 TOF-SIMS ion images in the positive-ion mode: a. sum of the $\mathrm{Cu}_{2} \mathrm{OH}^{+}$ions; $b$. sum of the $\mathrm{Cu}_{3}(\mathrm{OH})_{2}{ }^{+}$ions ; TOF-SIMS ion images in the negative ion mode: $\mathrm{c}$. $\mathrm{Cl}^{-}$ions; $\mathrm{d}$. sum of the $\mathrm{CuCl}_{2} \cdot \mathrm{CuOH}^{-}$ions; e. sum of fatty acid carboxylate ions and $\mathrm{f}$. two colors overlay between the sum of the $\mathrm{CuCl}_{2}^{-}$and $\mathrm{CuOH}^{-}$ions (green) and the fatty acid carboxylate ions (red). Field of view $200 \mu \mathrm{m} \times 200 \mu \mathrm{m} ; 256 \times$ 256 pixels, pixel size $0.78 \mu \mathrm{m}$, fluence $4.8 \times 10^{11}$ ions.cm ${ }^{-2}$. Color scale bars, with amplitude in number of counts, are indicated to the right of each ion image. The amplitude of the color scale corresponds to the maximum number of counts $\mathrm{mc}$ and could be read as $[0, \mathrm{mc}]$. tc is the total number of counts recorded for the specified $\mathrm{m} / \mathrm{z}$ (sum of counts in all the pixels). From Reference ${ }^{106}$. Copyright $($ ) 2011, American Society for Mass Spectrometry. Published by the American Chemical Society. All rights reserved.

Figure 6 Light microscopic image (A), representing the scanned SIMS area of the partially degraded vermilion paint of $\mathrm{MH} 251 / 26$. The arrow indicates the direction of the line scan. SIMS images of the sulfide (B) and chloride (C) represent the distribution of these ions over the partially degraded vermilion paint layer. The line scan (D) illustrates the distribution of chlorine and sulfur from top to bottom in the paint cross section. From reference ${ }^{11}$ Copyright $($ ) 2005, American Chemical Society.

Figure 7 Multivariate analysis comparing artificially aged reference organic binders and painting samples. Score plot of the ToF-SIMS data obtained for a secco samples 5,6 and 7 and for the artificially aged reference organic binders (rabbit glue, casein and whole egg), as well as the aged mixtures (casein and whole egg, rabbit glue and whole egg, casein and rabbit glue). The percent of variance described by PC1 and PC 2 are reported on the axes. The ellipses drawn around each group of data are a guide for the eye. From reference ${ }^{122}$ Copyright (C) 2015 Elsevier B.V. All rights reserved. 


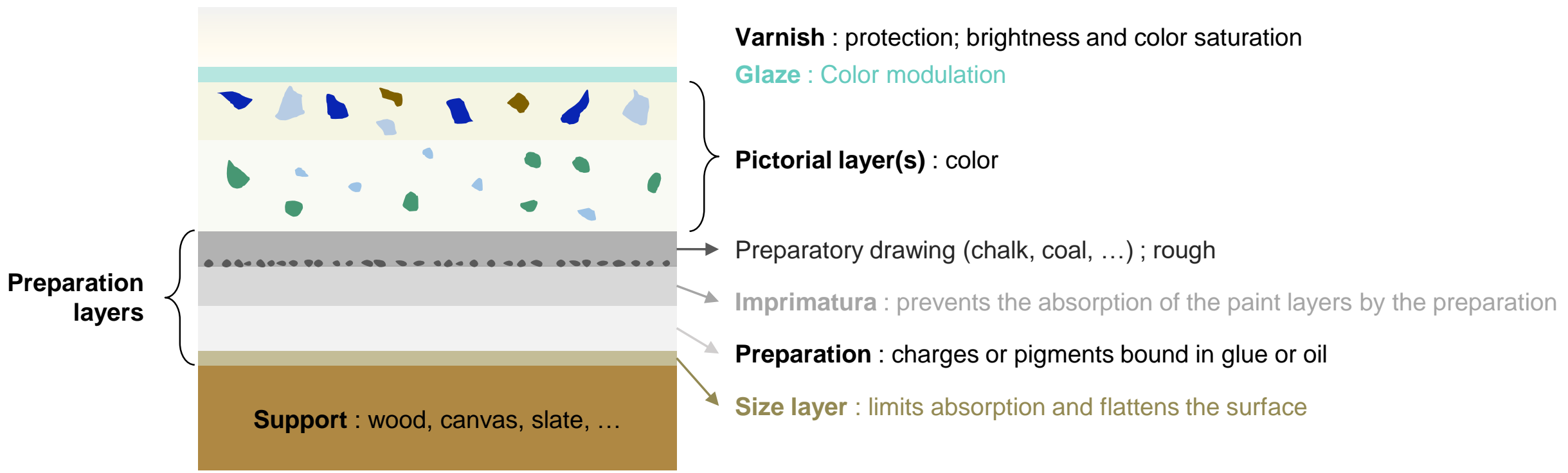

\section{Figure 1}


a. Infant Bacchanals, 1626

Nicolas Poussin

Palazzo Barberini, Rome, Italy

$56 \mathrm{~cm} \times 76,5 \mathrm{~cm}$

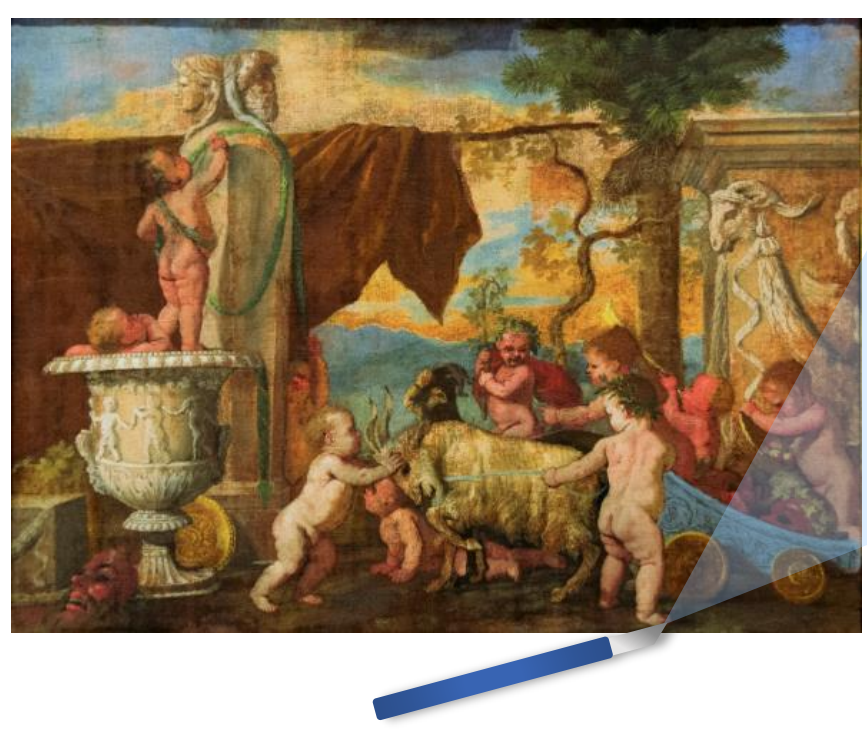

b.

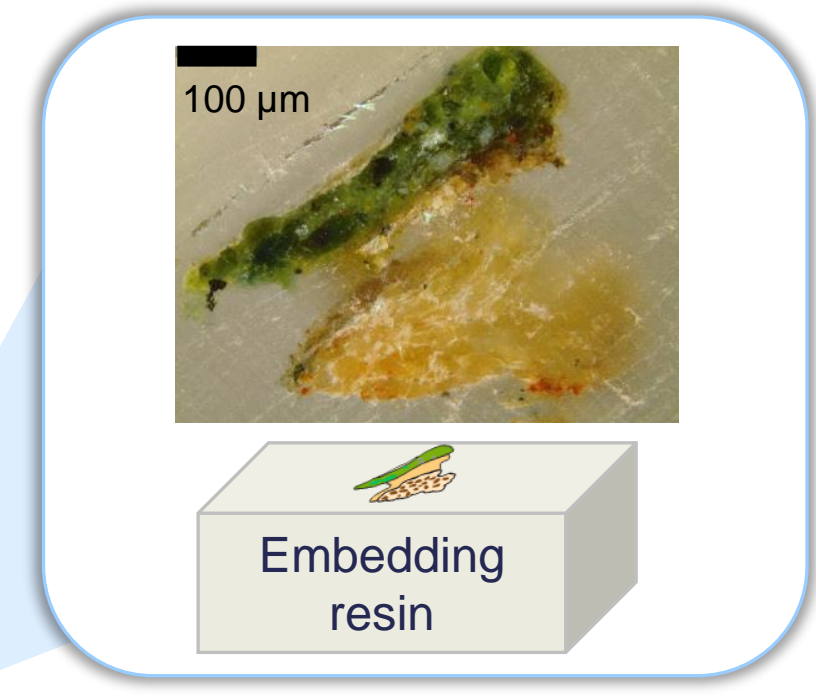

C.

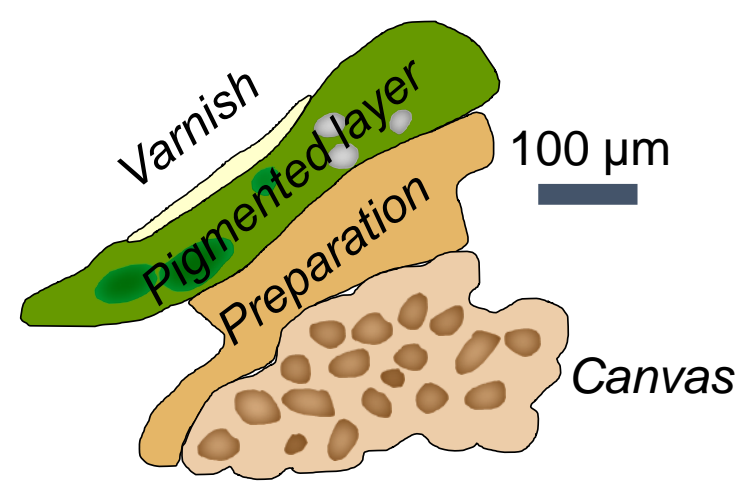

Figure 2 


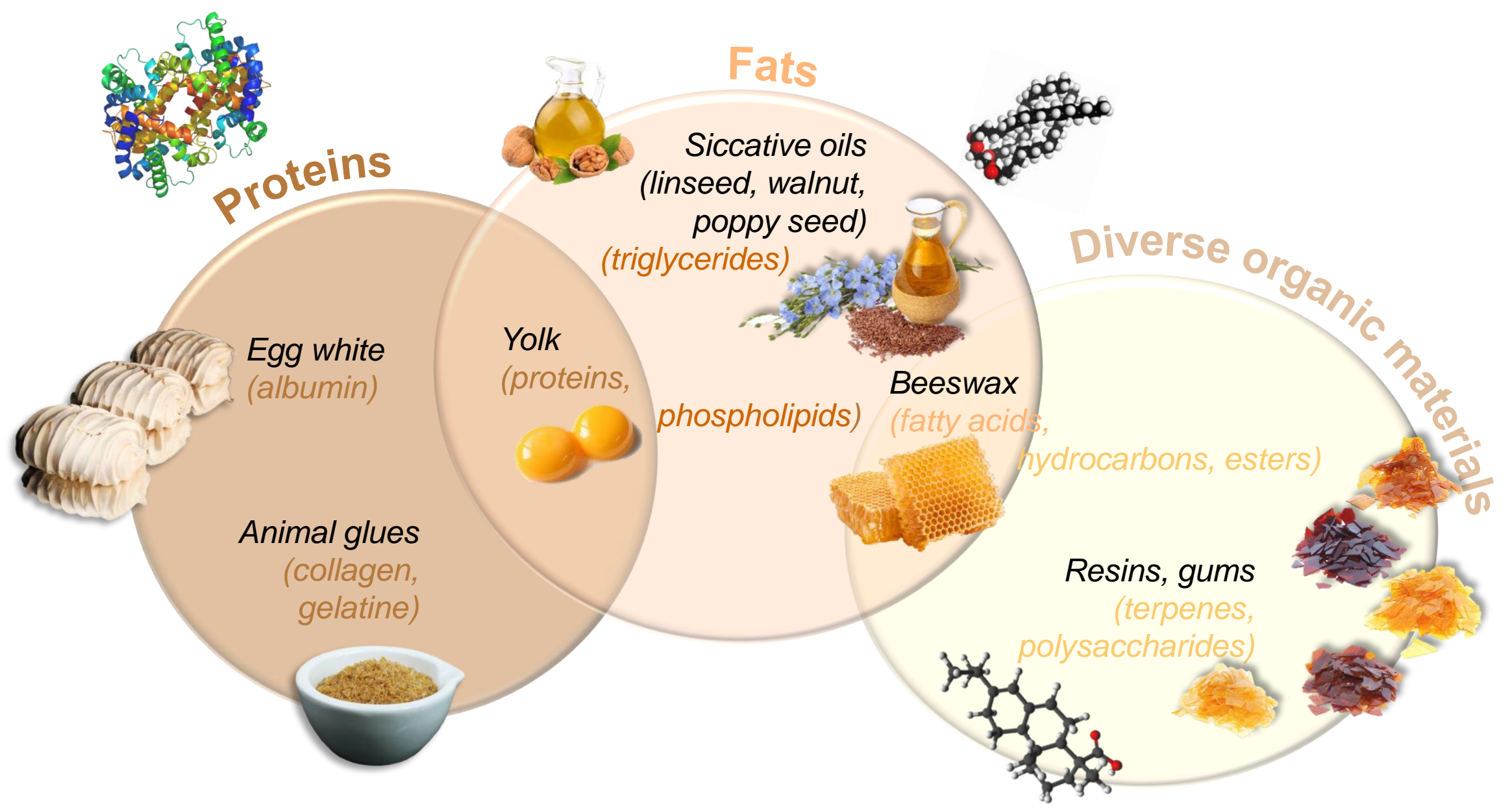

Figure 3 


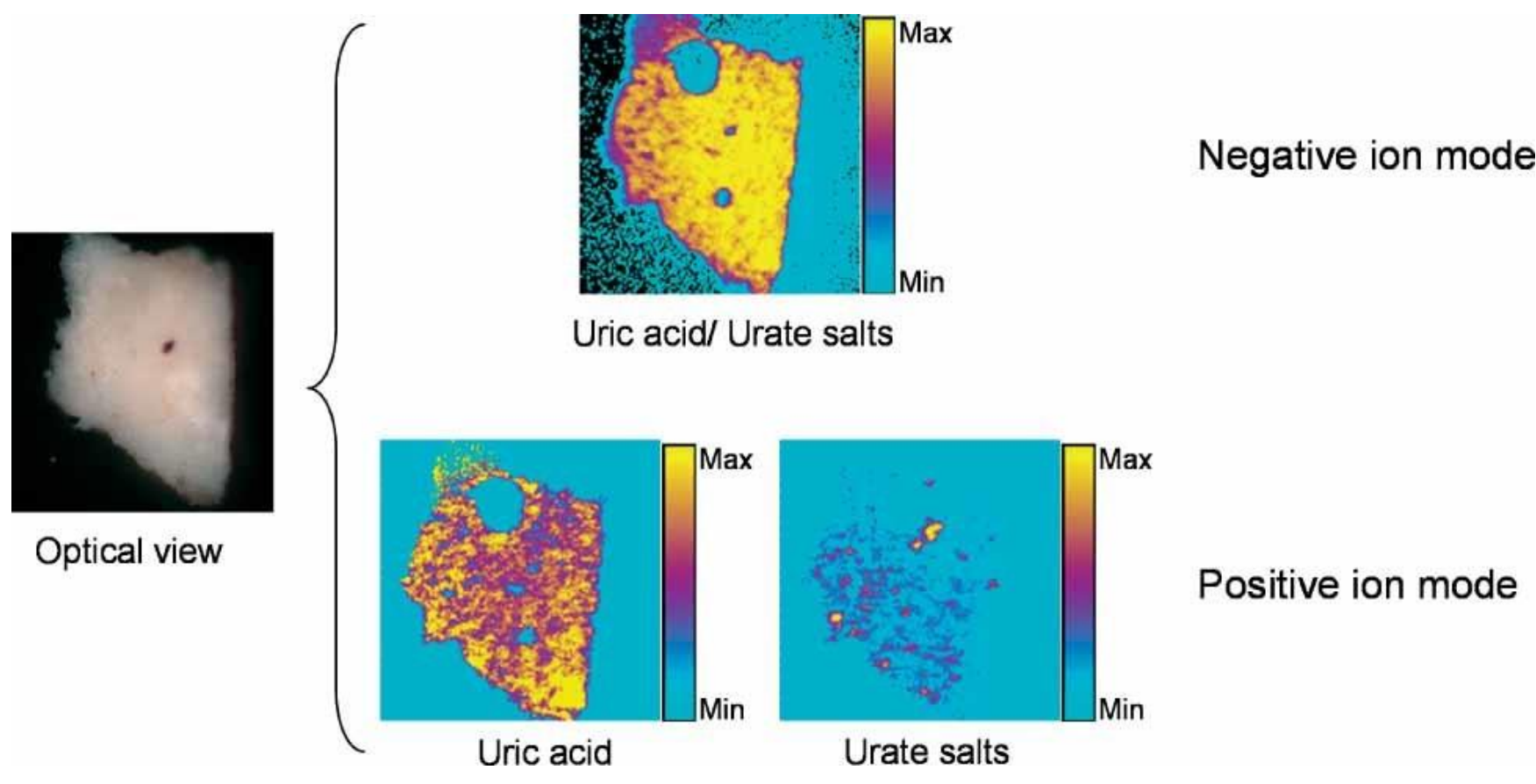

Figure 4 

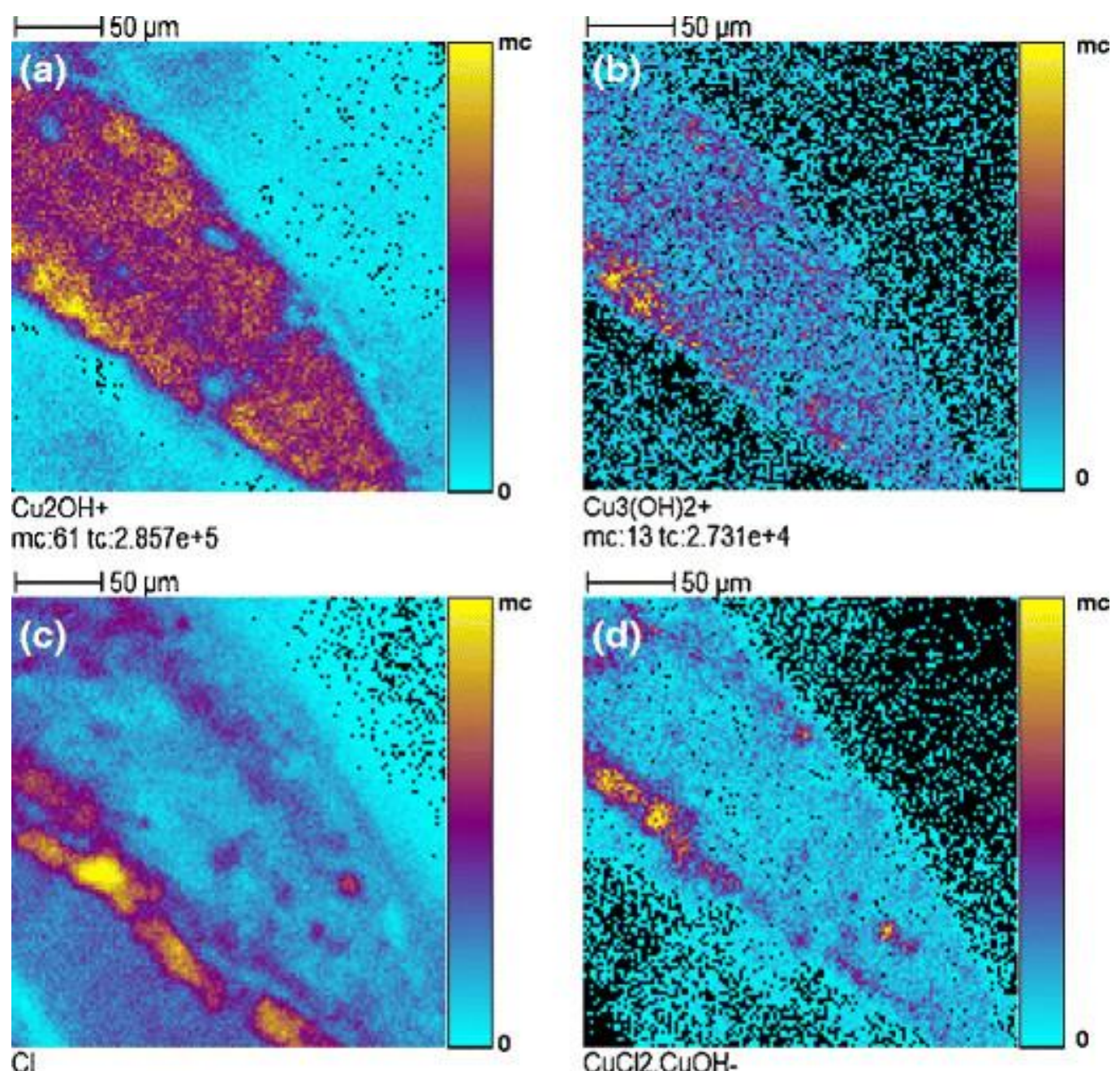

$\mathrm{mc}: 101 \mathrm{tc}: 3.988 \mathrm{e}+5$


$m c: 115$ tc: $4.155 \mathrm{e}+5$

Figure 5 

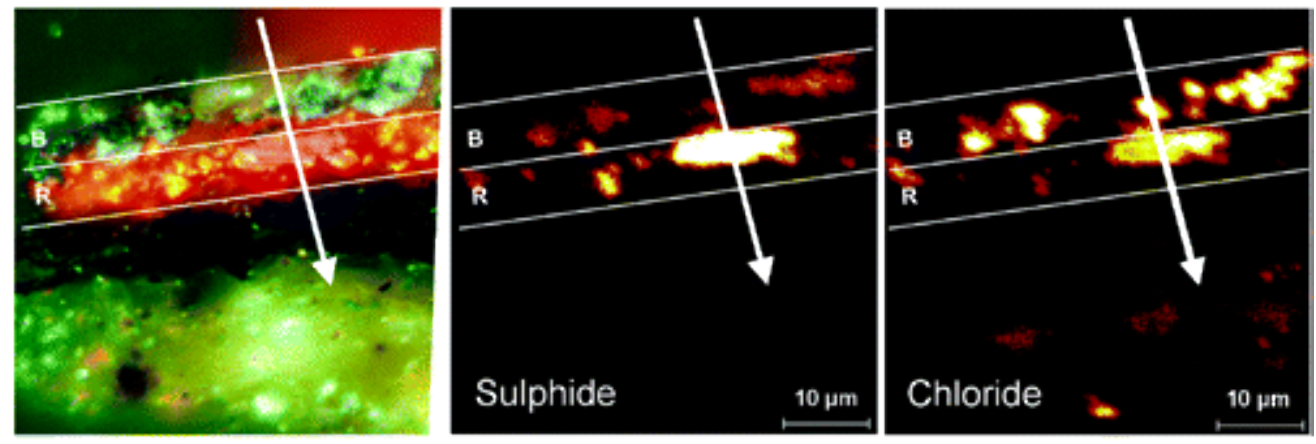

A

B

C

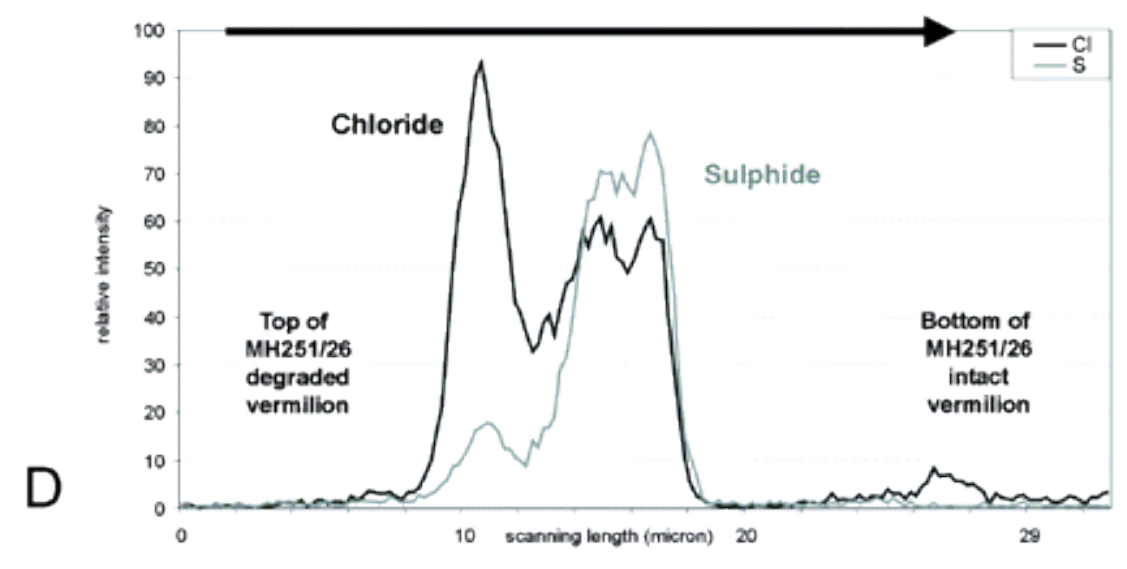

Figure 6 


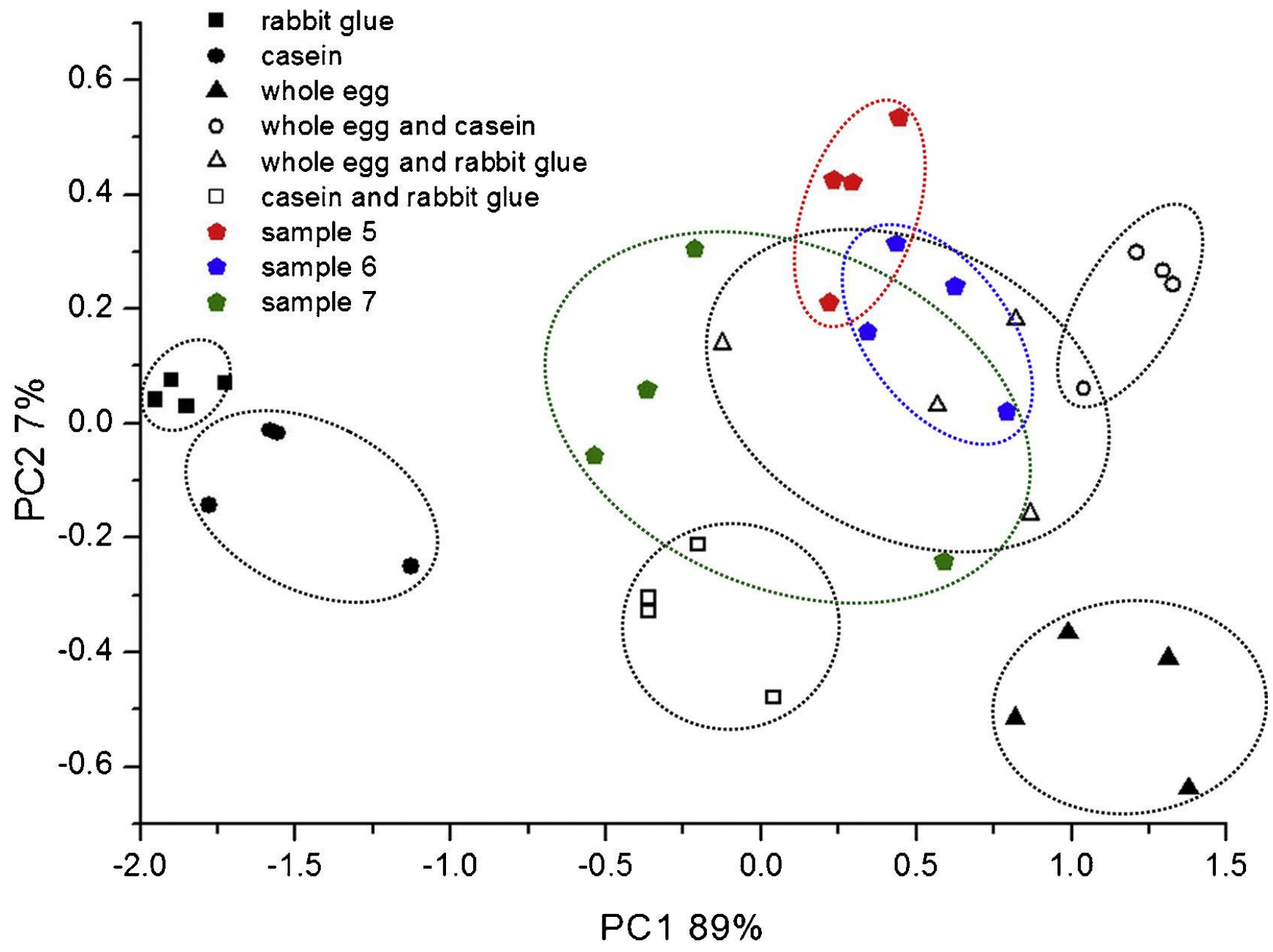

Figure 7 